Pablo Esteban Salinas Solís

\author{
Cálculo computacional do equilíbrio \\ metaestável de gases para a formação de \\ acetona a partir de etanol e estudo da \\ atividade química do carbono na metanação \\ de $\mathrm{CO} 2$
}

Dissertação de Mestrado

Dissertação apresentada ao Programa de PósGraduação em Engenharia de Materiais e de Processos Químicos e Metalúrgicos da PUC-Rio como requisito parcial para obtenção do grau de Mestre em Engenharia de Materiais e de Processos Químicos e Metalúrgicos.

Orientador: Prof. Roberto Ribeiro de Avillez 


\title{
Cálculo computacional do equilíbrio metaestável de gases para a formação de acetona a partir de etanol e estudo da atividade química do carbono na metanação de $\mathrm{CO} 2$
}

\begin{abstract}
Dissertação apresentada ao Programa de PósGraduação em Engenharia de Materiais e de Processos Químicos e Metalúrgicos da PUC-Rio como requisito parcial para obtenção do grau de Mestre em Engenharia de Materiais e de Processos Químicos e Metalúrgicos. Aprovada pela Comissão Examinadora abaixo assinada.
\end{abstract}

Prof. Roberto Ribeiro de Avillez Orientador Departamento de Engenharia Química e de Materiais - PUC-Rio

Profa. Sonia Letichevsky Departamento de Engenharia Química e de Materiais - PUC-Rio

Drā. Lucia Gorestin Appel Instituto Nacional de Tecnologia - INT

Prof. Marcio da Silveira Carvalho Coordenador Setorial do Centro Técnico Científico - PUC-Rio 
Todos os direitos reservados. É proibida a reprodução total ou parcial do trabalho sem autorização da universidade, do autor e do orientador.

\section{Pablo Esteban Salinas Solis}

Graduou-se em Engenharia Química pela Pontifícia Universidade Católica do Rio de Janeiro (Rio de Janeiro, Brasil).

Ficha Catalográfica

\section{Salinas Solís, Pablo Esteban}

Cálculo computacional do equilíbrio metaestável de gases para a formação de acetona a partir de etanol e estudo da atividade química do carbono na metanação de CO2 / Pablo Esteban Salinas Solís ; orientador: Roberto Ribeiro de Avillez. - 2018.

55 f. : il. color. ; $30 \mathrm{~cm}$

Dissertação (mestrado)-Pontifícia Universidade Católica do Rio de Janeiro, Departamento de Engenharia Química e de Materiais, 2018.

Inclui bibliografia

1. Engenharia de Materiais - Teses. 2. Engenharia Química - Teses. 3. Síntese de acetona a partir de etanol. 4. Catalisadores. 5. Metanação. 6. Atividade química do carbono. 7. Cálculo termodinâmico de equilíbrio. I. Avillez, Roberto Ribeiro de. II. Pontifícia Universidade Católica do Rio de Janeiro. Departamento de Engenharia Química e de Materiais. III. Título. 


\section{Agradecimentos}

Aos meus pais, Victor e Fanny, e meu irmão Juan por sempre acreditarem no meu potencial e sempre me apoiarem e ajudarem.

Ao meu orientador Prof. Roberto de Avillez pelo apoio e suporte no desenvolvimento deste trabalho, sem o qual não seria possível tê-lo finalizado.

À PUC-Rio universidade que me acolheu desde a graduação.

À Dra. Lucia Appel e Prof. Sonia Letichevsky por aceitarem participar da comissão examinadora.

À minha namorada Isabella Queiroz por continuar me apoiando mesmo eu cancelando encontros para escrever este trabalho.

Ao meu amigo Artur Serpa por me acompanhar desde a graduação e me ajudar até o presente.

À minha amiga Bia Lemos por aguentar minhas reclamações e problemas na pesquisa.

Aos meus amigos Alexandre Canellas, André Araújo, André Nogueira, Bruno Todeschini, Fillipo Impellizieri, Jayme Barros, Otávio P. Luz, Vinicus Nascimento e Zeca Carvalho por me distrair nos momentos de lazer. 


\section{Resumo}

Salinas-Solis, Pablo Esteban; de Avillez, Roberto Ribeiro. Cálculo computacional do equilíbrio metaestável de gases para a formação de acetona a partir de etanol e estudo da atividade química do carbono na metanação de $\mathbf{C O}_{2}$. Rio de Janeiro, 2018. 55p. Dissertação de Mestrado Departamento de Engenharia Química e de Materiais, Pontifícia Universidade Católica do Rio de Janeiro.

Esta tese tem como objetivo estudar a viabilidade termodinâmica da reação de acetona a partir de etanol e água realizando cálculos utilizando o programa Thermo-Calc e a base de dados SSUB3 para equilíbrios de gases metaestáveis. Para a validação do método utilizado inicialmente foi calculado o equilíbrio para a reação da metanação de $\mathrm{CO}_{2}$ com $\mathrm{H}_{2}$, esse cálculo ocorreu sem grandes problemas e ainda foi adicionado o estudo da atividade química do carbono para evitar deposição de carbono sólido nos catalisadores. Para os cálculos da acetona foi considerado um equilíbrio metaestável pois ele não foi calculado utilizando todas as espécies químicas possíveis, isso foi feito para simular o efeito de catalisadores, que inibem a formação de algumas dessas espécies, já que se o cálculo fosse feito sem levar isso em conta se notou que a reação que ocorre é a de reforma do etanol pela água. A conversão de etanol e a seletividade das espécies químicas presentes em maior quantidade foram determinadas em função da temperatura e da razão de etanol e água, e os resultados obtidos foram comparados com dados experimentais obtidos com catalisadores diversos.

\section{Palavras-chave}

Síntese de acetona a partir de etanol; Catalisadores; Metanação; Atividade química do carbono; Cálculo termodinâmico de equilíbrio 


\section{Abstract}

Salinas-Solis, Pablo Esteban; de Avillez, Roberto Ribeiro (Advisor). Computer calculation of metastable gas equilibrium for the acetone synthesis from ethanol and evaluation of the chemical activity of carbon on the methanation of $\mathbf{C O}_{2}$. Rio de Janeiro, 2018. 55p. Dissertação de Mestrado - Departamento de Engenharia Química e de Materiais, Pontifícia Universidade Católica do Rio de Janeiro.

The mean goal of this thesis is to study the thermodynamic viability of the acetone formation reaction from ethanol and water by performing calculations using the program Thermo-Calc and the SSUB3 database for metastable gas equilibrium. As a validation of the method used the equilibrium was calculated for the methanation reaction of $\mathrm{CO}_{2}$ with $\mathrm{H}_{2}$. This calculation occurred without problems so the study of the chemical activity of the carbon was also added to avoid the deposition of solid carbon on the catalysts. For the acetone calculation, it was considered a metastable equilibrium because it was not possible to calculate using all possible chemical species. This was done to simulate the effects of catalysts, which inhibit the formation of some of these species. If the calculation was made with all chemical species, it was noted that the net reaction is the reform of ethanol by water.The conversion of ethanol and the selectivity of the chemical species present in greater quantities were determined as a function of temperature and ethanol and water ratio, and the results obtained were compared with experimental data obtained with different catalysts.

\section{Keywords}

Acetone synthesis from ethanol; Catalysts; Methanation; Carbon chemical activity; Calculation of thermodynamic equilibrium. 


\section{Sumário}

1 Introdução 12

2 Objetivos 14

2.1. Objetivos gerais 14

2.2. Objetivos específicos 14

3 Revisão bibliográfica $\quad 15$

3.1. Equilíbrio termodinâmico $\quad 15$

3.2. Atividade química 16

3.3. Catalisadores 16

3.4. Metanação 17

3.4.1. Catalisadores da metanação 19

3.5. Acetona 19

3.5.1. Mecanismo de formação da Acetona 20

3.6. Thermo-Calc 22

4 Metodologia computacional $\quad 24$

4.1. Metanação 24

4.2. Acetona 24

4.3. Atividade química do carbono 25

5 Resultados e discussões $\quad 26$

5.1. Metanação 26

5.1.1. Influência da razão dos gases $\mathrm{H}_{2} / \mathrm{CO}_{2} \quad 26$

5.1.2. Influência da temperatura 27

5.1.3. Conversão do $\mathrm{CO}_{2} \quad 29$

5.1.4. Atividade química do carbono na metanação 30

5.2. Formação da acetona 32

5.2.1. Cálculo do equilíbrio inicial 32

5.2.2. Equilíbrios metaestáveis 35

5.2.3. Influência da razão etanol/água e da temperatura no equilíbrio metastável40

5.2.4. Espécies relevantes encontradas 43

5.2.5. Atividade química do carbono 46 
6 Conclusão

7 Sugestões de trabalhos futuros

8 Referências bibliográficas 


\section{Lista de figuras}

Figura 1 - Produção de metano para diferentes frações molares de $\mathrm{CO}_{2} \ldots \ldots \ldots . .26$

Figura 2 - Influência da temperatura na produção de metano. ...........................27

Figura 3 - Influência da temperatura e da pressão na produção de metano

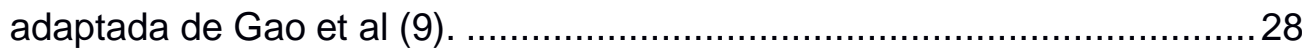

Figura 4 - Conversão de $\mathrm{CO}_{2}$ calculados para diferentes temperaturas .............29

Figura 5 - Conversão de $\mathrm{CO}_{2}$ calculados por Gao,J e adaptada de sua

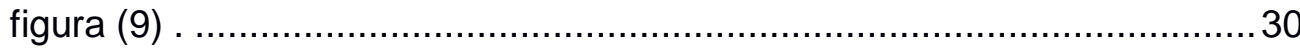

Figura 6 - Atividade química do carbono para a diferentes temperaturas............31

Figura 7 - Atividade química do carbono para diferentes concentrações

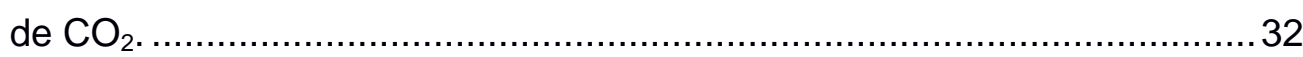

Figura 8 - Formação de acetona por diferentes catalisadores (8). .....................35

Figura 9 - Conversão de etanol.................................................................. 41

Figura 10 - Seletividade da Acetona. ......................................................... 43

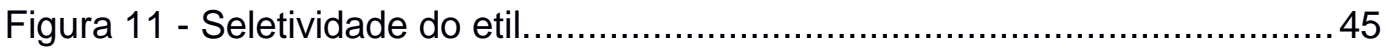

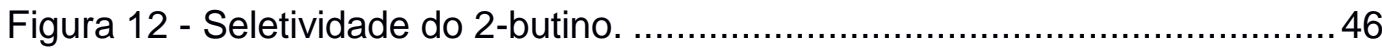

Figura 13 - Atividade Química do Carbono. ................................................. 47 


\section{Lista de tabelas}

Tabela 1 - Componentes presentes no equilíbrio........................................... 33

Tabela 2 - Quantidade de acetona formada................................................... 34

Tabela 3 - Componentes encontrados no equilíbrio metaestável. .......................36

Tabela 4 - Seletividade da acetona em diferentes equilíbrios metaestáveis.......37

Tabela 5 - Componentes encontrados no Teste 8....................................... 40

Tabela 6 - Conversão de etanol. ................................................................... 41

Tabela 7 - Quantidade molar de acetona ..................................................... 42

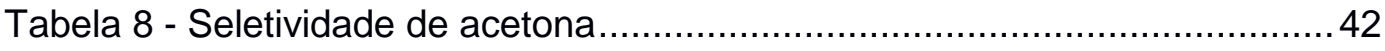

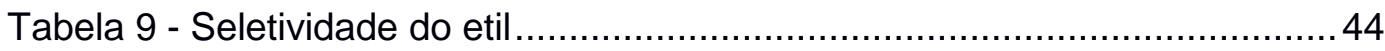

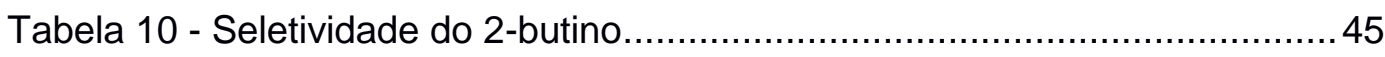

Tabela 11 - Atividade Química do Carbono ....................................................47 
Tenho que correr tô atrasado e vou ficando pra tras, e na minha idade eles já tinham tudo e até um pouco mais. $\mathbf{S} \mathbf{U}$ a $\mathbf{V} \quad \mathbf{V}$ E, Ninguém vai me ouvir, Alaska. 


\section{1 \\ Introdução}

No mundo moderno cada vez se busca mais técnicas para produção de produtos com o objetivo de serem renováveis e menos poluentes. Os reagentes que mais são evitados são os de origem fóssil. No presente trabalho foi estudado um método alternativo para a produção de acetona com isso em mente.

A acetona é principalmente utilizada na indústria química como intermediária e como solvente em fármacos (1). Seu uso mais importante na atualidade é na produção de precursores da síntese de metacrilato de metila e ácido metacrílico que são monômeros de polímeros muito produzidos (2).

A maior parte da acetona mundial é produzida pelo processo do cumeno, e é um subproduto da produção de fenol (3). Essa reação utiliza como reagentes o benzeno e o propileno, e tem como produtos finais a acetona, o fenol e diversas espécies em menores quantidades, como a acetofenona e o metilestireno (4). Esse processo é responsável por até 95\% da produção mundial de acetona (5).

Um dos problemas relacionados a esse processo é que o fenol é altamente tóxico e corrosivo. O envenenamento por esta substância pode ocorrer pelo ar, solo ou água (6). Além disso, apesar do fenol ser de interesse econômico, os mercados são diferentes, o que leva a um maior custo de logística e armazenamento. Como as matérias primas são de origem fóssil é importante encontrar um outro método para a sua produção, buscando diminuir a emissão de produtos tóxicos e utilizando matérias primas renováveis.

Uma alternativa viável sugerida seria a utilização do etanol como matéria prima do processo, essa opção é ainda mais interessante no Brasil, já que em 2018 houve uma produção de 647,6 milhões de toneladas de cana-de-açúcar uma das principais matérias primas utilizadas no mundo para a produção de etanol, e 26,45 bilhões de litros do álcool (7). Essa alternativa já foi estudada por Silva-Calpa(8).

Outro composto de suma importância no mundo moderno é o metano, utilizado principalmente como combustível e sua produção também ocorre por métodos verdes, no caso será estudada a metanação de $\mathrm{CO}_{2}$ por $\mathrm{H}_{2}$ que além de formar o metano, também se livra de um poluente, o $\mathrm{CO}_{2}$, fazendo com que 
esse processo seja ainda mais interessante do ponto de vista ambiental. Esse meio alternativo já foi muito estudado nos trabalhos de Gao et al (9), Su (10), Goodman (11), Ronsch et al (12) e Sutton (13).

No presente estudo foram calculados os equilíbrios termodinâmicos das reações de metanação de $\mathrm{CO}_{2}$ por $\mathrm{H}_{2}$ e da formação de acetona a partir de etanol e água. A proposta era comparar os resultados calculados com os obtidos em laboratório e encontrar condições ideais de temperatura, pressão e razão de alimentação em ambos os casos para obter maiores conversões e evitar a formação de carbono sólido. 


\section{2}

\section{Objetivos}

\section{1.}

\section{Objetivos gerais}

Realizar o cálculo computacional do equilíbrio na reação de metanação de $\mathrm{CO}_{2}$ com $\mathrm{H}_{2}$ e definir as condições que impedem a formação de carbono sólido, capaz de envenenar os catalisadores e parar a reação.

Realizar o cálculo computacional da reação de formação da acetona a partir do etanol e água empregando condições restritivas para simular a ação de catalisadores.

\section{2.}

\section{Objetivos específicos}

1. Calcular a razão ideal de $\mathrm{H}_{2} / \mathrm{CO}_{2}$ para a metanação e comparar com a literatura.

2. Calcular a influência da temperatura na reação de metanação e comparar com a literatura;

3. Calcular a atividade química do carbono para estudar a possível formação de carbono sólido;

4. Determinar que condições de equilíbrio com restrições e, portanto, metaestável favorecem a formação da acetona;

5. Calcular a influência da razão de etanol/água e da temperatura no equilíbrio metaestável para a formação da acetona;

6. Calcular a atividade química do carbono com o objetivo de impedir a formação de carbono sólido. 


\section{3 \\ Revisão bibliográfica}

\section{1.}

\section{Equilíbrio termodinâmico}

Um sistema é considerado em equilíbrio quando suas propriedades se mantêm constantes ao longo do tempo se não houver interferências externas (14). Para reações químicas o modo mais prático para estudar o equilíbrio sob condições de temperatura e pressão constante é calcular a variação da energia de Gibbs do sistema (15) para diferentes condições de reação, reagentes iniciais e produtos finais. O equilíbrio será obtido para a maior redução de energia de Gibbs e, portanto, o máximo de trabalho útil que pode ser obtido. A equação 1 mostra como essa propriedade é calculada.

$$
G=H-T S
$$

Onde $\mathrm{H}$ representa a entalpia do sistema, $\mathrm{T}$ a sua temperatura e $\mathrm{S}$ a entropia.

Para o sistema estar em equilíbrio é necessário que essa energia seja minimizada (16), para isso se estuda a forma diferencial, que está representada na equação 2.

$$
d G=-S d T+V d P+\sum \mu_{i} d n_{i}
$$

Onde S representa a entropia do sistema, dT a variação de temperatura, $\mathrm{V}$ o volume, dP a variação na pressão do sistema, $\mu_{\mathrm{i}}$ representa o potencial químico do componente i e $\mathrm{dn}_{\mathrm{i}}$ a variação do número de mols do componente i.

Para temperatura e pressão constantes, essa equação pode ser reescrita como na equação 3.

$$
d G)_{P, T}=\sum \mu_{i} d n_{i}
$$


E para se chegar ao mínimo da energia de Gibbs, basta fazer com que a derivada dela seja igual a zero, com isso pode se dizer que o equilíbrio ocorrerá quando a equação 4 for verdadeira.

$$
d G)_{P, T}=\sum \mu_{i} d n_{i}=0
$$

Também existe o conceito de equilíbrio metaestável, que mesmo não sendo o mínimo global da energia livre de Gibbs do sistema corresponde a um mínimo local e, portanto, uma condição de equilíbrio. Neste trabalho o equilíbrio metaestável foi simulado eliminando certas espécies químicas do cálculo de minimização.

Gao et al (9) utilizaram esses mesmos conceitos para o cálculo termodinâmico da metanação, mas utilizaram programas diferentes dos deste trabalho para esses cálculos.

\section{2.}

\section{Atividade química}

A atividade química é um conceito relacionado ao equilíbrio dinâmico entre fases (17). Pode-se dizer que a atividade química mede a tendência de uma molécula mudar de fase, ou seja, uma atividade química baixa indica que não haverá mudança de fase (18). De modo geral, pode-se relacionar a atividade química de um componente com o seu potencial químico de acordo com a equação 5.

$$
\mu_{i}=G_{i}+R \operatorname{RTn} a_{i}
$$

Como a atividade química é um conceito entre fases, ela não tem influência em substâncias puras, por isso para soluções e sólidos puros, a atividade química é igual a 1.

\section{3.}

\section{Catalisadores}

Um catalisador é uma substância que transforma reagentes em produtos através de um ciclo repetido de passos elementares no qual ele participa e é regenerado à sua forma original no final de cada ciclo (19). Os catalisadores não 
afetam a termodinâmica da reação, apenas facilitam e aceleram as reações. Geralmente é preferencial utilizar a catálise heterogênea, em que o catalisador constitui a uma fase diferente dos reagentes e dos produtos, já que facilita uma futura separação dos produtos, mesmo ela tendo algumas desvantagens como uma cinética mais complexa e geralmente menores seletividades.

A catálise heterogênea resulta de sítios ativos na superfície dos sólidos, ou seja, locais específicos na superfície do catalisador onde ocorre uma interação com o reagente, e ocorre a reação. Identificar os intermediários da reação e o seu mecanismo costuma ser difícil, principalmente para reações na fase gasosa. (20). Isso gera uma dificuldade nos cálculos termodinâmicos, já que normalmente não se sabe exatamente as reações favorecidas no processo nem as espécies intermediárias.

Como a catálise ocorre na superfície dos catalisadores, diversos fatores podem levar a sua desativação. Em processos envolvendo hidrocarbonetos o mais comum é ocorrer a deposição de carbono sólido, ocupando os sítios ativos do catalisador (21) e tornando-o inutilizável, até ser feita uma regeneração.

\section{4. Metanação}

O metano é de grande importância para setores industriais, de energia e transporte em todo o mundo (22) e por isso, a metanação é uma reação muito estudada. Ela pode ser feita tanto a partir do $\mathrm{CO}_{2}$ quanto do $\mathrm{CO}$, ambos gases considerados poluentes e gerados em grandes quantidades. Por exemplo, em 2009, os Estados Unidos geravam cerca de 6 bilhões de toneladas de $\mathrm{CO}_{2}$ por ano (23) com aparentemente grande impacto ambiental. No entanto, esse número também mostra uma grande disponibilidade de matéria prima para a formação do metano e uma necessidade de se transformá-la em algo não poluente (24).

O processo de metanação do $\mathrm{CO}_{2}$ foi descoberto pelo químico francês Paul Sabatier (25) e é utilizado até hoje tanto para a produção de metano quanto para a produção de água, já que é um método viável para a obtenção de água. $A$ equação 6 mostra essa reação.

$$
\mathrm{CO}_{2}+4 \mathrm{H}_{2} \leftrightarrow \mathrm{CH}_{4}+\mathrm{H}_{2} \mathrm{O}
$$


Porém essa não é a única reação possível envolvida na metanação, todas as outras reações possíveis de ocorrerem durante o processo de metanação se encontram a seguir $(26,27)$ :

$$
\begin{gathered}
\mathrm{CO}+3 \mathrm{H}_{2} \leftrightarrow \mathrm{CH}_{4}+\mathrm{H}_{2} \mathrm{O} \\
2 \mathrm{CO}+2 \mathrm{H}_{2} \leftrightarrow \mathrm{CH}_{4}+\mathrm{CO}_{2} \\
2 \mathrm{CO} \leftrightarrow \mathrm{C}+\mathrm{CO}_{2} \\
\mathrm{CO}+\mathrm{H}_{2} \mathrm{O} \leftrightarrow \mathrm{CO}_{2}+\mathrm{H}_{2} \\
\mathrm{CH}_{4} \leftrightarrow 2 \mathrm{H}_{2}+\mathrm{C} \\
\mathrm{CO}+\mathrm{H}_{2} \leftrightarrow \mathrm{C}+\mathrm{H}_{2} \mathrm{O} \\
\mathrm{CO}_{2}+2 \mathrm{H}_{2} \leftrightarrow \mathrm{C}+2 \mathrm{H}_{2} \mathrm{O} \\
n \mathrm{CO}+(2 \mathrm{C}+1) \mathrm{H}_{2} \leftrightarrow \mathrm{C}_{n} \mathrm{H}_{2 n+2}+n \mathrm{H}_{2} \mathrm{O}
\end{gathered}
$$

Como todas essas reações podem ocorrer simultaneamente, qualquer variação nas condições de temperatura, pressão ou razão de alimentação afeta consideravelmente a composição dos produtos (9).

Um dos efeitos estudados foi a formação de carbono sólido na metanação de $\mathrm{CO}$ a altas temperaturas e altas concentrações de $\mathrm{CO}$, essa formação levou a desativação de vários catalisadores utilizados (28-30), isso pode ser explicado pela reação de Bourdouard, vista na equação 9, mas as reações 11, 12 e 13 também podem concorrer para a deposição de carbono sólido.

Outro efeito estudado foi a formação de $\mathrm{CO}$ na metanação de $\mathrm{CO}_{2}$ a altas temperaturas, isso leva a um alto consumo de $\mathrm{CO}_{2}$ e piora a produção de 
metano, isso se deve pela predominância da reação reversa de deslocamento da água (reverse water gas shift) (equação 10) a temperaturas acima de $550{ }^{\circ} \mathrm{C}$ (9) (31). Também é importante notar que normalmente na corrente de $\mathrm{CO}_{2}$ também há CO presente, então vale a pena ambos serem considerados.

\subsubsection{Catalisadores da metanação}

A metanação a partir de $\mathrm{CO}_{2}$ é muito favorecida termodinamicamente (32), por isso não seria necessária uma simulação de um possível efeito de catalisadores, já que todo $\mathrm{o} \mathrm{CO}_{2}$ reagiria formando metano com facilidade e estudamos apenas a condição de equilíbrio. Porém os catalisadores se notam necessários pelas limitações cinéticas da reação, então nesse caso o catalisador seria apenas para acelerar a reação. Além disso o cálculo inicial sempre é realizado sem a interferência de catalisadores, pois eles não mudam a termodinâmica, apenas alteram mecanismos.

Dentre os mais estudados e utilizados estão os catalisadores a base de níquel suportados em diversos óxidos $\left(\mathrm{TiO}_{2}, \mathrm{SiO}_{2}, \mathrm{Al}_{2} \mathrm{O}_{3}, \mathrm{CeO}_{2}, \mathrm{ZrO}_{2}\right)$. O níquel é preferido pois possui alta seletividade e um custo muito baixo, se comparado a outros metais que também podem ser utilizados, como o ródio e o rutênio. $O$ catalisador de níquel, porém, tem a desvantagem de sofrer desativação a baixas temperaturas (33).

\section{5. \\ Acetona}

As três maiores fontes de demanda da acetona são o uso em solventes, tanto para pinturas quanto para indústria farmacêutica $(5,34)$, produção de metacrilato de metila (MMA) e a síntese de bis-fenol A (BPA) (35). Existe uma previsão de que a demanda global aumente ao longo dos anos, por isso é importante encontrar meios mais eficientes para a sua produção (34).

Cerca de $97 \%$ da acetona mundial (34) é produzida utilizando o processo do cumeno (5), a reação pode ser vista na equação 16 :

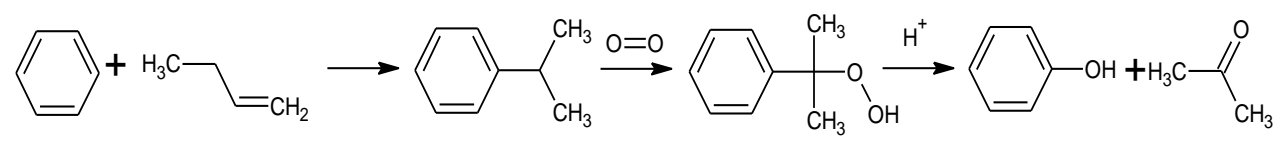


Porém, como mostra a equação 16, além de utilizar matérias primas de origem fóssil, a sua produção é atrelada ao fenol, um composto altamente tóxico e corrosivo (6). Por isso, no passado, alguns autores (36-41) estudaram os mecanismos para essa síntese utilizando como reagentes etanol e água, segundo a equação 17:

$$
2 \mathrm{C}_{2} \mathrm{H}_{5} \mathrm{HO}+\mathrm{H}_{2} \mathrm{O} \rightarrow \mathrm{CH}_{3} \mathrm{COCH}_{3}+4 \mathrm{H}_{2}+\mathrm{CO}_{2}
$$

Todos esses estudos focaram na utilização de diferentes catalisadores para sugerir uma rota para a reação, mas nenhum deles fez um estudo termodinâmico da reação.

\subsection{1.}

\section{Mecanismo de formação da Acetona}

Murthy et al (36) utilizaram três sistemas a base de óxido de ferro para estudar essa reação, os sistemas foram $\mathrm{Fe}_{2} \mathrm{O}_{3}-\mathrm{MnO}, \mathrm{Fe}_{2} \mathrm{O}_{3}-\mathrm{ZnO}$ e $\mathrm{Fe}_{2} \mathrm{O}_{3}-\mathrm{CaO}$. Os catalisadores $\mathrm{MnO}$ - e $\mathrm{CaO}$ - foram desativados rapidamente, se dando preferência ao de $\mathrm{ZnO}$-, que teve uma maior estabilidade. Foram sugeridas duas rotas para essa reação, na primeira ocorre uma desidrogenação do etanol formando acetaldeído (equação 18) que por sua vez seria oxidado para a formação de ácido acético (equação 19) e depois seria feita a ketonização para a formação da acetona (equação 20). Na segunda rota sugerida, o primeiro passo é a equação 18 para a formação do acetaldeído, seguida da condensação aldólica formando butan-1-al-3-ol (equação 21) que é desidrogenado a buten-3ona-1-al (equação 22) que por sua vez poderá formar ou acetona e ácido fórmico (equação 23) ou ácido acético e acetaldeído(equação 24). No caso da formação do acetaldeído ocorreria uma ketonização para formar a acetona (equação 20)

$$
\begin{gathered}
\mathrm{C}_{2} \mathrm{H}_{5} \mathrm{OH} \rightarrow \mathrm{CH}_{3} \mathrm{CHO}+\mathrm{H}_{2} \\
2 \mathrm{CH}_{3} \mathrm{CHO}+\mathrm{O}_{2} \rightarrow 2 \mathrm{CH}_{3} \mathrm{COOH} \\
2 \mathrm{CH}_{3} \mathrm{COOH} \rightarrow \mathrm{CH}_{3} \mathrm{COCH}_{3}+\mathrm{CO}_{2}+\mathrm{H}_{2} \mathrm{O} \\
2 \mathrm{CH}_{3} \mathrm{CHO} \rightarrow \mathrm{CH}_{3} \mathrm{CH}(\mathrm{OH}) \mathrm{CH}_{2} \mathrm{CHO}
\end{gathered}
$$




$$
\begin{gathered}
\mathrm{CH}_{3} \mathrm{CH}(\mathrm{OH}) \mathrm{CH}_{2} \mathrm{CHO}-\mathrm{H}_{2} \rightarrow \mathrm{CH}_{3} \mathrm{COH}_{2} \mathrm{CHO} \\
\mathrm{CH}_{3} \mathrm{COH}_{2} \mathrm{CHO}+\mathrm{H}_{2} \mathrm{O} \rightarrow 2 \mathrm{CH}_{3} \mathrm{COCH}_{3}+2 \mathrm{HCOOH} \\
\mathrm{CH}_{3} \mathrm{COH}_{2} \mathrm{CHO}+\mathrm{H}_{2} \mathrm{O} \rightarrow 2 \mathrm{CH}_{3} \mathrm{COOH}+2 \mathrm{CH}_{3} \mathrm{CHO}
\end{gathered}
$$

Nakajima et al (37) realizaram um estudo com diversos catalisadores para encontrar o mais eficiente para o processo, e também obteve como o ideal o $\mathrm{Fe}_{2} \mathrm{O}_{3}-\mathrm{ZnO}$. A rota proposta começou novamente com a desidrogenação do etanol (equação 18), e após isso seguiu as seguintes equações.

$$
\begin{gathered}
\mathrm{CH}_{3} \mathrm{CHO}+\mathrm{OH}^{-} \rightarrow \mathrm{CH}_{3} \mathrm{CO}_{2}^{-}+\mathrm{H}_{2} \\
\mathrm{CH}_{3} \mathrm{CO}_{2}^{-}+\mathrm{H}^{+} \rightarrow \mathrm{CH}_{3} \mathrm{CO}^{+}+\mathrm{OH}^{-} \\
\mathrm{CH}_{3} \mathrm{CO}_{2}^{-}+\mathrm{CH}_{3} \mathrm{CO}^{+} \rightarrow \mathrm{CH}_{3} \mathrm{COCH}_{3}+\mathrm{CO}_{2}
\end{gathered}
$$

Yee et al (38) utilizaram dois tipos de catalisadores diferentes, $\mathrm{CeO}_{2} \mathrm{e}$ $\mathrm{Pd} / \mathrm{CeO}_{2}$, e observaram uma rota diferente para cada um deles. Para $\circ \mathrm{CeO}_{2}$ se observou a formação do acetaldeído em duas etapas (equação 28), após isso foi observada a mesma rota inicialmente observada por Murthy et al (36), equações 19 e 20, porém foi constatado que a oxidação do acetaldeído ocorre com o oxigênio presente na superfície do catalisador.

$$
\mathrm{C}_{2} \mathrm{H}_{5} \mathrm{OH} \rightarrow \mathrm{CH}_{3} \mathrm{CH}_{2} \mathrm{O}+\mathrm{H} \rightarrow \mathrm{CH}_{3} \mathrm{CHO}+\mathrm{H}_{2}
$$

Para o $\mathrm{Pd} / \mathrm{CeO}_{2}$ inicialmente se considerou a formação do acetaldeído novamente pela equação 28 , ele perde hidrogênio para formar acetilo (equação 29), que reage para a formação da acetona (equação 30 ).

$$
\begin{aligned}
& 2 \mathrm{CH}_{3} \mathrm{CHO} \rightarrow 2 \mathrm{CH}_{3} \mathrm{CO}+\mathrm{H}_{2} \\
& 2 \mathrm{CH}_{3} \mathrm{CO} \rightarrow \mathrm{CH}_{3} \mathrm{COCH}_{3}+\mathrm{CO}
\end{aligned}
$$

Idriss et al (39) estudaram o efeito de seis catalisadores diferentes, obtendo o melhor resultado para o $\mathrm{TiO}_{2}$, os três produtos principais observados foram acetaldeído, acetona e acetato de etila. A rota da reação foi descrita como sendo a mesma observada por Murthy et al (36) equações 18, 19 e 20. 
Nishiguchi et al (40) estudaram o uso de catalisadores de $\mathrm{CuO} / \mathrm{CeO}_{2}$ e a adição de $\mathrm{MgO}$ a esse catalisador. O mecanismo proposto começa com a equação 18, e após isso ocorre uma condensação aldólica como na equação 21. A espécie formada reage com $\mathrm{O}_{2}$ na superfície do catalisador de acordo com a equação 31 gerando intermediários, que são desidrogenados e decarboxilados gerando a acetona (equação 32).

$$
\begin{array}{r}
\mathrm{CH}_{3} \mathrm{CH}(\mathrm{OH}) \mathrm{CH}_{2} \mathrm{CHO}+\mathrm{O}_{(s)} \rightarrow \mathrm{CH}_{3} \mathrm{CH}(\mathrm{OH}) \mathrm{CH}_{2} \mathrm{COO}_{(s)}+\mathrm{H}_{(s)} \\
\mathrm{CH}_{3} \mathrm{CH}(\mathrm{OH}) \mathrm{CH}_{2} \mathrm{COO}_{(s)}+\mathrm{H}_{(s)} \rightarrow \mathrm{CH}_{3} \mathrm{COCH}_{3}+\mathrm{CO}_{2}+\mathrm{H}_{2}
\end{array}
$$

Pode-se notar que mesmo tendo equações parecidas, não existe um consenso em relação ao mecanismo exato da reação, mas Rodrigues et al (41) estudaram os mecanismos sugeridos pelos autores e foi proposto um mecanismo que segue primeiramente a equação 28 para formação do acetaldeído em duas etapas, depois ocorre uma redução do catalisador segundo a equação 19, após isso a ketonização segundo a equação 20 , e por fim a recuperação do catalisador, reagindo com $\mathrm{O}^{2-}$ dissociado da água.

Silva-Calpa (8) também fez um estudo desses trabalhos, e junto com testes de laboratório propôs um mecanismo similar onde, inicialmente, o etanol se adsorve na superfície do catalisador formando espécies etóxido, que por sua vez sofrem desidrogenação oxidativa formando acetaldeído, conforme a equação 28. Que reage com o oxigênio na rede cristalina gerando espécies acetato conforme a equação 19 , nessa reação ocorre a redução do catalisador. As espécies acetato sofrem ketonização conforme a equação 20 para a formação da acetona. E para finalizar o ciclo catalítico a água se dissocia e reoxida o catalisador.

Pode-se observar que a presença do $\mathrm{O}_{2}$ é muito importante para a reação de formação da acetona a partir do etanol.

\section{6.}

\section{Thermo-Calc}

O Thermo-Calc é um software para a realização de cálculos termodinâmicos pela minimização da energia de Gibbs total de um dado sistema. 
Ele pode empregar diversas bases de dados termodinâmicos dependendo dos sistemas estudados(42) Ele tem sido mais utilizado para diagramas de propriedades e diagramas de fases associados à metalurgia e sistemas de materiais inorgânicos. No entanto, ele permite cálculos para diversos materiais não inorgânicos, tais como, por exemplo, polímeros e gases de substâncias orgânicas. 


\section{4 \\ Metodologia computacional}

\section{1. Metanação}

Para utilizar o Thermo-Calc para calcular os equilíbrios na metanação o primeiro passo foi definir uma base de dados adequada para se trabalhar, a escolhida foi a SSUB3 (SGTE Substance Database v3.3) (44) por se tratar da melhor para equilíbrios entre gases. Depois disso, foram escolhidos os elementos que estariam presentes no equilíbrio: carbono, hidrogênio e oxigênio. Por se tratar de uma reação na fase gasosa na qual pode haver deposição de carbono sólido, foram desconsideradas todas as outras fases possíveis. Após isso, foram determinadas as condições do sistema (temperaturas, pressões e número de mol de cada componente) sugeridos por Gao et al (8) para cada situação e foram coletados os dados do equilíbrio calculado. Os dados foram tratados utilizando o programa QtiPlot (45).

\section{2.}

Acetona

Para o utilizar o Thermo-Calc para calcular os equilíbrios na formação da acetona também foi utilizada a base SSUB3, mas nesse caso os elementos presentes nesse equilíbrio foram: carbono, hidrogênio, oxigênio e nitrogênio. Novamente apenas foram consideradas no cálculo as fases gasosas e o carbono na forma sólida de grafite para servir de referência para o carbono. Para simular o efeito dos catalisadores também foram rejeitadas algumas espécies químicas que não foram observadas experimentalmente, ou estavam em quantidades muito pequenas, nos testes de desempenho catalítico feitos no laboratório por Silva-Calpa (8). Esse equilíbrio termodinâmico pode ser considerado um equilíbrio metaestável. Para determinar que espécies seriam rejeitadas foram feitos diversos testes rejeitando as espécies formadas em maiores quantidades e observando se a sua retirada favoreceria, ou não, a formação de acetona. Após a determinação dessas espécies foram determinadas as condições do sistema (temperaturas, pressões e número de mol de cada componente) para cada 
situação e foram coletados os dados do equilíbrio calculado. Os dados foram tratados utilizando o programa QtiPlot (45).

\section{3.}

\section{Atividade química do carbono}

Como cálculo adicional, tanto para a metanação quanto para a produção de acetona a fase grafite do carbono foi incluída e sua condição modificada para DORMANT, isso significa que para o cálculo de equilíbrio foi considerado que essa fase não seria formada, mas mesmo assim é feito o cálculo da força motriz para a formação dela, se ela for positiva haverá uma tendência à formação da fase. Desse modo o carbono sólido não será formado, o estado de referência do carbono também foi modificado para a fase sólida. Com essas modificações, é possível observar sob que condições o carbono sólido poderá ser formado, ou não, a partir da atividade química do mesmo, ela sendo maior que 1 o carbono sólido poderá ser formado. Isso pode ser visto pela equação 5 .

$$
\mu_{i}=G_{i}+R T \ln a_{i}
$$

Sendo $G_{i}$ igual ao valor de $\mu_{\mathrm{i}}$ no estado de referência. Como a referência escolhida foi a própria fase de carbono sólido pode ser visto que quando o valor da atividade química for menor que 1 , o potencial químico do carbono será menor que o da fase grafite, não havendo formação, se for igual a 1 os potenciais químicos ficariam iguais mostrando que o potencial químico do carbono seria igual ao da fase carbono sólido, por isso, havendo a sua formação. Como a fase havia sido definida como DORMANT essa formação não ocorre, permitindo que a atividade seja maior que 1 e mostrando uma tendência 


\section{5 \\ Resultados e discussões}

5.1.

Metanação

\subsection{1.}

Influência da razão dos gases $\mathrm{H}_{2} / \mathrm{CO}_{2}$

O primeiro cálculo realizado foi a verificação da influência da razão dos gases de entrada no processo da metanação do $\mathrm{CO}_{2}$, para isso foi calculada a produção de metano para diferentes frações molares de $\mathrm{CO}_{2}$ mantendo temperatura a $300^{\circ} \mathrm{C}$, a pressão a $101325 \mathrm{~Pa}$ e o número total de mol igual a 1 . Esses valores de temperatura e pressão foram escolhidos por serem os observados na literatura como valores ideias para a reação. A composição inicial dos gases continha apenas $\mathrm{CO}_{2}$ e $\mathrm{H}_{2}$. Os dados obtidos se apresentam na Figura 1.

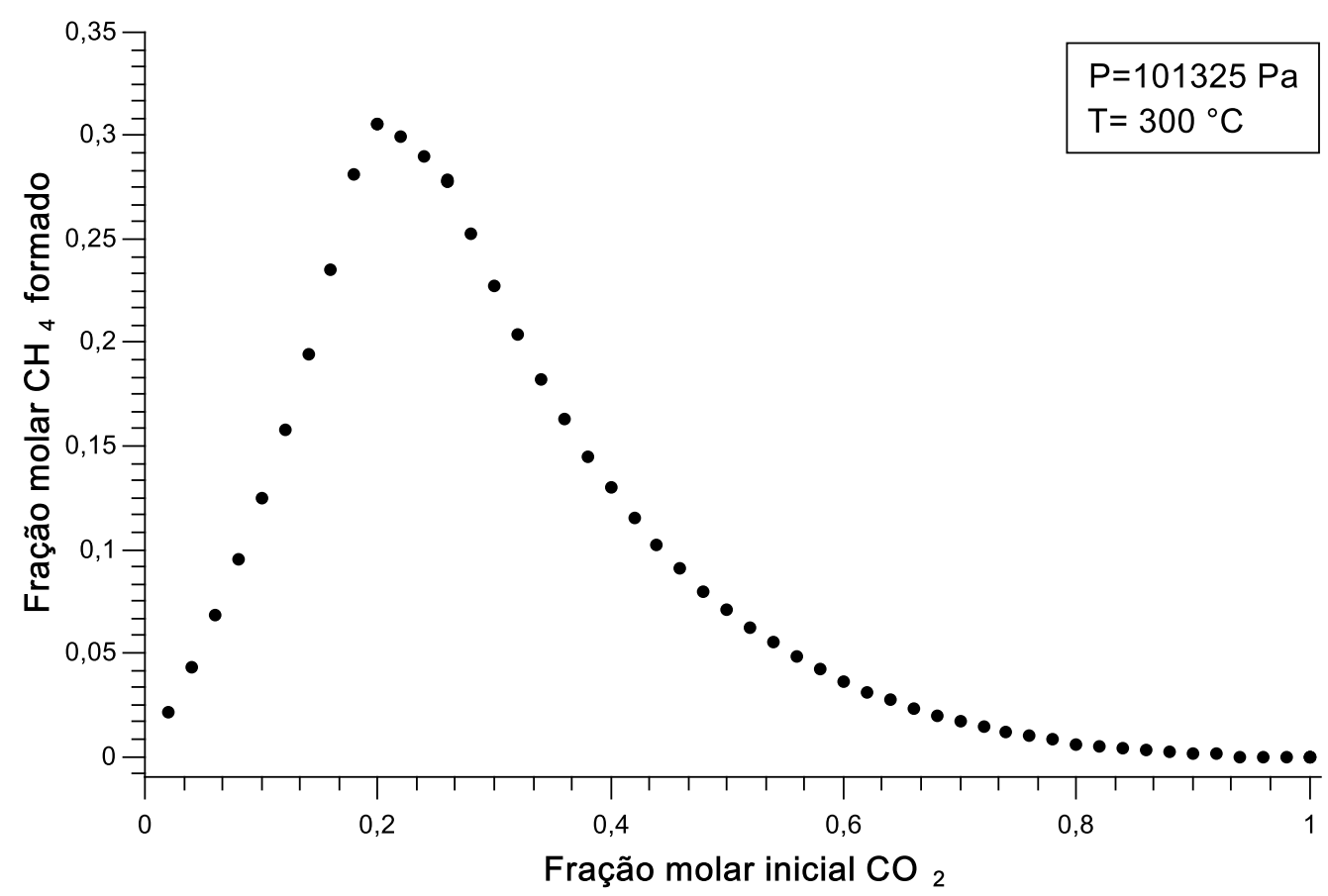

Figura 1 - Produção de metano para diferentes frações molares de $\mathrm{CO}_{2}$ 
Pelos cálculos feitos pode ser observado que ocorre um máximo na formação de metano quando a fração molar de entrada de $\mathrm{CO}_{2}$ é próximo a 0,2, isso demonstra uma razão de $\mathrm{H}_{2} / \mathrm{CO}_{2}$ de 4 . Esse valor coincide com 0 encontrado por Gao et al (9) e utilizado no trabalho de Su et al (10), normalmente essa razão é utilizada também por ser a razão estequiométrica da reação. Essa razão será utilizada como referência constante para o resto dos cálculos da metanação.

\subsection{2.}

\section{Influência da temperatura}

Para determinar a influência da temperatura nessa reação foram calculados diversos equilíbrios variando esse parâmetro, o cálculo foi realizado para temperaturas entre $200{ }^{\circ} \mathrm{C}$ e $800{ }^{\circ} \mathrm{C}$, esses valores foram escolhidos pois foram os mesmos utilizados por Gao (9) e isso facilita a comparação. Os seguintes valores foram mantidos constantes: pressão total em $101325 \mathrm{~Pa}$, razão molar $\mathrm{H}_{2} / \mathrm{CO}_{2}$ em 4 e número total de moles em 1 . Os resultados encontrados estão apresentados na Figura 2.

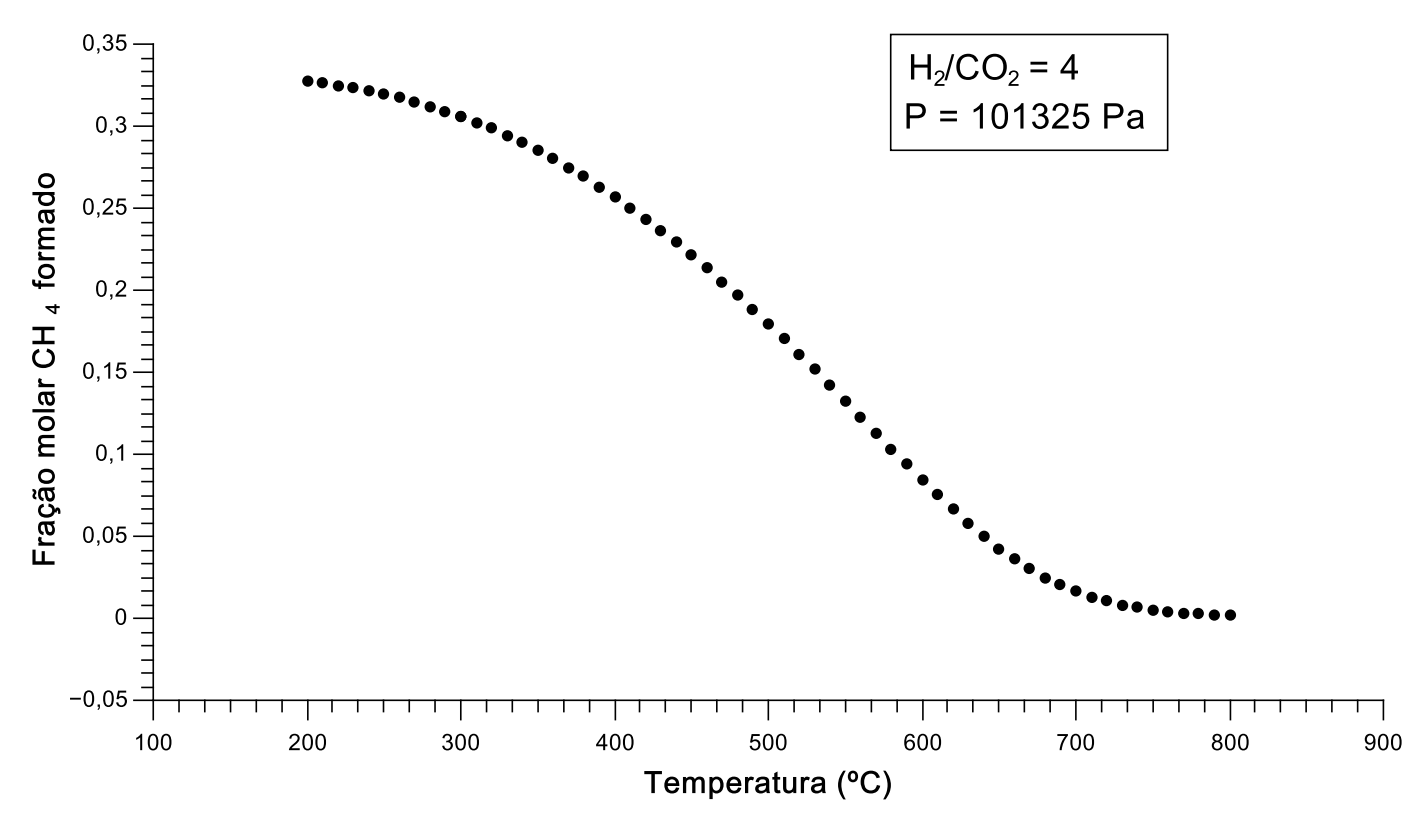

Figura 2 - Influência da temperatura na produção de metano.

Com isso se verifica o efeito da temperatura na metanação, podemos ver que quanto menores as temperaturas, maior é a produção de metano, isso é explicado pela equação 33 . 


$$
\mathrm{CO}_{2}+4 \mathrm{H}_{2} \leftrightarrow \mathrm{CH}_{4}+2 \mathrm{H}_{2} \mathrm{O}
$$

Utilizando as entalpias de formação de cada elemento podemos calcular a entalpia da reação, temos que segundo Cox et al. (46)

$$
\Delta_{\mathrm{f}} \mathrm{H}^{\circ}{ }_{\mathrm{CO} 2}=-393,51 \mathrm{~kJ} / \mathrm{mol} \text { e } \Delta_{\mathrm{f}} \mathrm{H}^{\circ}{ }_{\mathrm{H} 2 \mathrm{O}}=-241,826 \mathrm{~kJ} / \mathrm{mol}
$$

E segundo Chase (47) $\Delta_{\mathrm{f}} \mathrm{H}_{\mathrm{C} 1 \mathrm{H} 4}^{\circ}=-74,87 \mathrm{~kJ} / \mathrm{mol}$, com isso chegamos a uma entalpia da reação de $-165,01 \mathrm{~kJ} / \mathrm{mol}$, o que mostra que a reação é exotérmica, então era esperado seu favorecimento a baixas temperaturas.

Esse resultado também foi encontrado por Gao et al (9) e pode ser visto na Figura 3, eles sugeriram o uso de temperaturas de no máximo $300{ }^{\circ} \mathrm{C}$. Ronsch et al (12) e Goodman (11) também obtiveram resultados semelhantes.

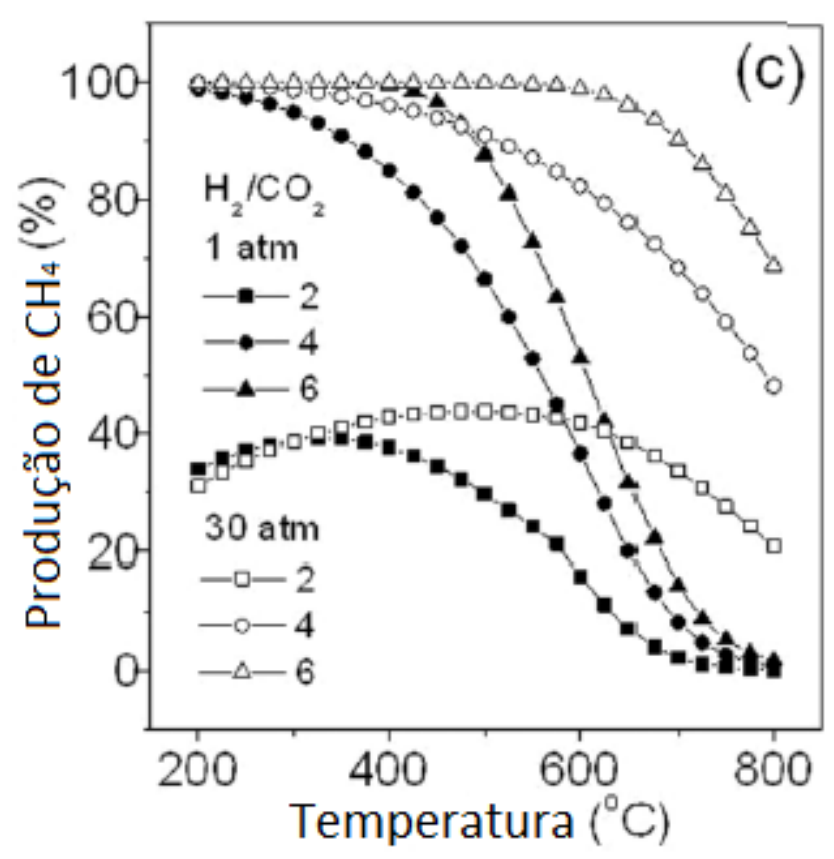

Figura 3 - Influência da temperatura e da pressão na produção de metano adaptada de Gao et al (9)

Na Figura 3 os cálculos foram feitos a pressões diferentes e razões diferentes de $\mathrm{H}_{2} / \mathrm{CO}_{2}$. Para a comparação com a Figura 2 é necessário observar a curva com círculos preenchidos, pois se tratam das mesmas condições estudadas. Observando a Figura 3 pode-se notar que não é necessário realizar o cálculo a pressões elevadas pois se vê pouca diferença na produção a baixas 
temperaturas, que são as que a favorecem. Além disso é sempre preferível trabalhar com processos a pressão atmosférica, já que pressões diferentes dessa aumentam o custo do processo.

\subsection{3.}

\section{Conversão do $\mathrm{CO}_{2}$}

A Figura 4 mostra os valores de conversão de $\mathrm{CO}_{2}$ calculados para a diferentes temperaturas, razão de $\mathrm{H}_{2} / \mathrm{CO}_{2}$ igual a 4 e pressão igual a $101325 \mathrm{~Pa}$.

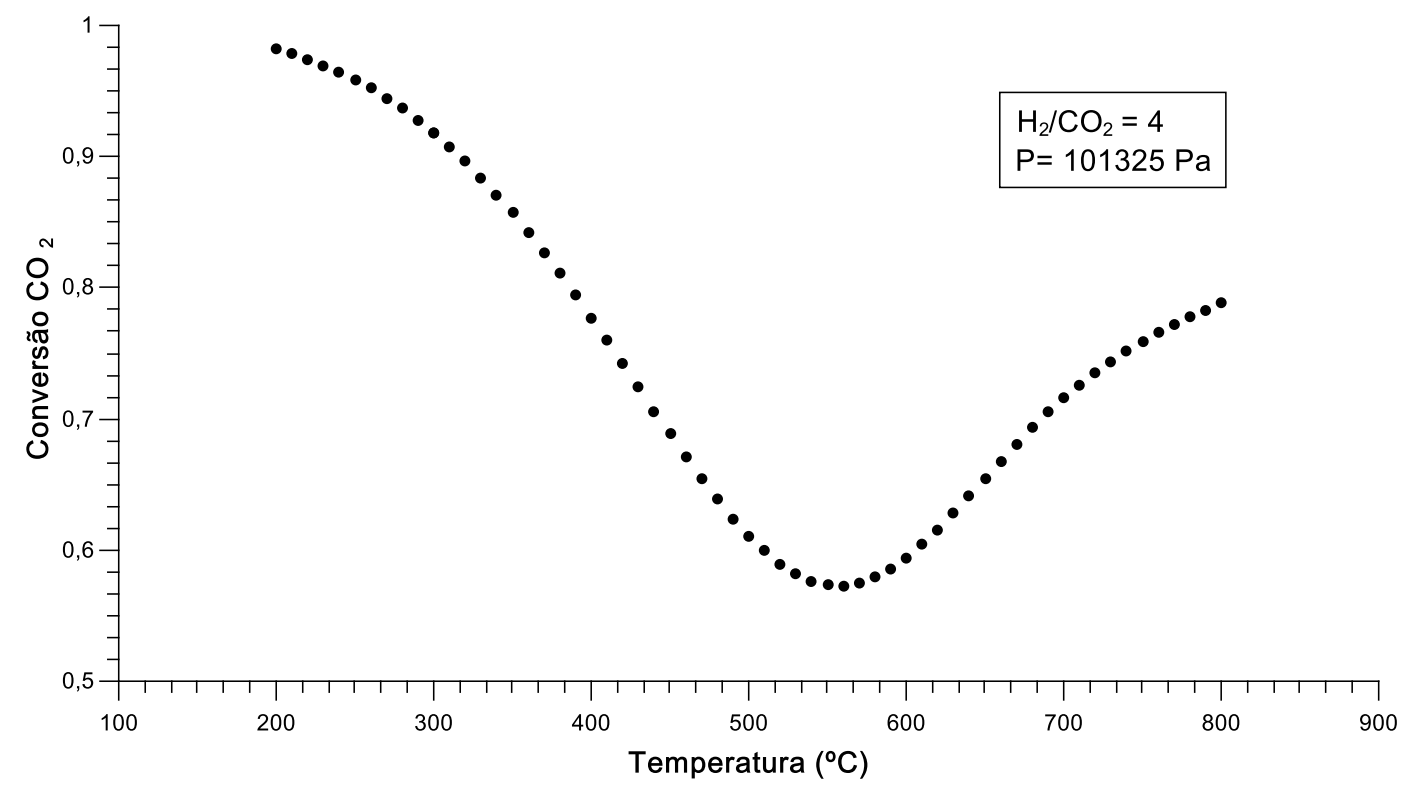

Figura 4 - Conversão de $\mathrm{CO}_{2}$ calculados para diferentes temperaturas

$\mathrm{Na}$ Figura 4 pode-se observar que a temperaturas baixas ocorre uma conversão quase que completa do $\mathrm{CO}_{2}$ e com o aumento das temperaturas essa conversão diminui até atingir um valor próximo a $60 \%$ em uma temperatura próxima a $550{ }^{\circ} \mathrm{C}$. Esse gráfico pode ser comparado com o calculado por Gao (9) presente na Figura 5. No qual se nota que ambas as curvas possuem o mesmo formato e são muito semelhantes. 


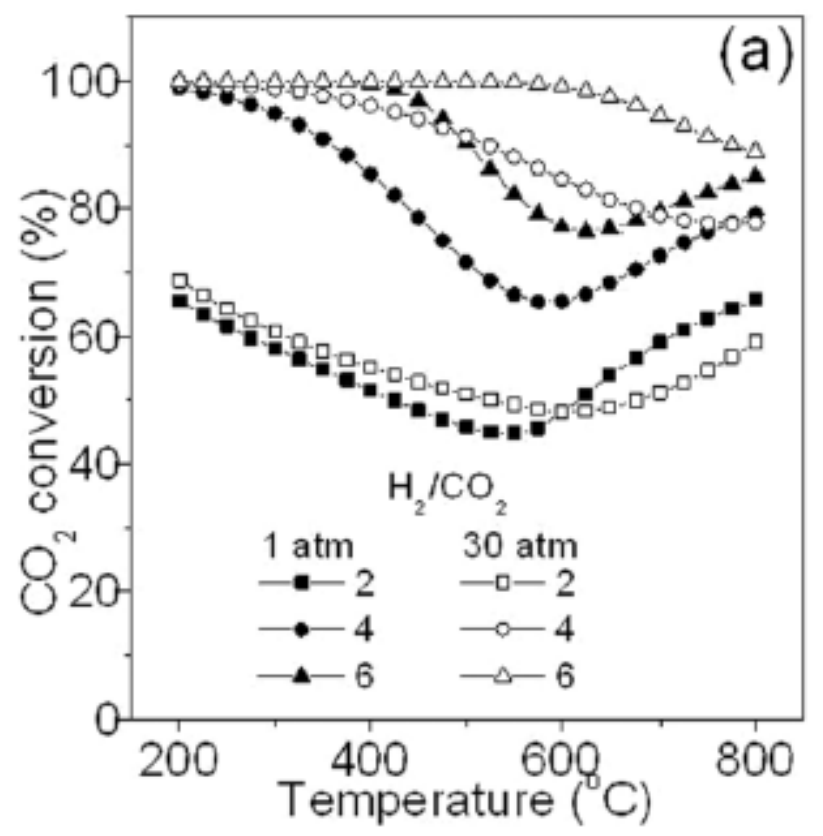

Figura 5 - Conversão de $\mathrm{CO}_{2}$ calculados por Gao,J e adaptada de sua figura (9) .

Após esse valor de mínimo atingido podemos notar que a conversão de $\mathrm{CO}_{2}$ volta a aumentar, o que poderia indicar que a reação desejada poder ser favorecida tanto a temperaturas baixas quanto muito altas, mas como foi visto anteriormente no tópico 5.1.3, isso não é o que ocorre.

Esse aumento na conversão pode ser explicado porque a reação de metanação não é a única que ocorre nesse sistema, nesse caso também ocorre a reação conhecida como water-gas shift reaction que se vê na equação 34 .

$$
\mathrm{CO}+\mathrm{H}_{2} \mathrm{O} \leftrightarrow \mathrm{CO}_{2}+\mathrm{H}_{2}
$$

Essa reação foi amplamente estudada por Pantagonis e Gunugunuri (48) e foi visto que a temperaturas altas a formação de CO passa a ser muito favorecida, por isso ocorre esse aumento na conversão de $\mathrm{CO}_{2}$.

\subsection{4.}

\section{Atividade química do carbono na metanação}

Além dos cálculos da metanação para validar o método utilizado, também foi feito um cálculo adicional da atividade química do carbono na reação, que não foi realizado por nenhum dos pesquisadores mencionados. Isso é 
interessante pois pode nos mostrar se haverá a presença de carbono sólido no equilíbrio dessa reação.

$\mathrm{Na}$ Figura 6 podemos ver como a temperatura vai afetar a atividade química do carbono para a razão de $\mathrm{H}_{2} / \mathrm{CO}_{2}$ de 4 e pressão de $101325 \mathrm{~Pa}$.

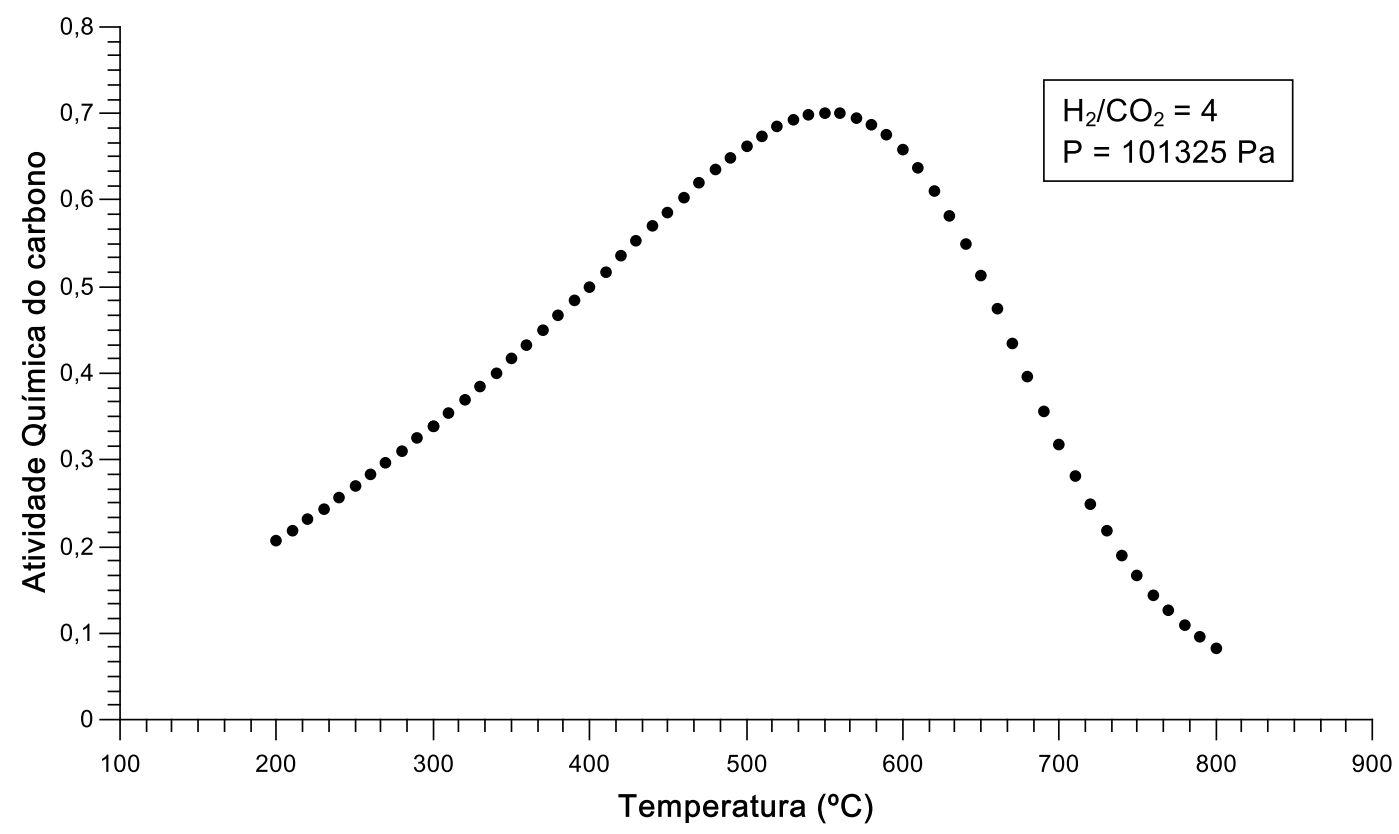

Figura 6 - Atividade química do carbono para a diferentes temperaturas

Pode-se observar na Figura 6 que independentemente da temperatura estudada, em todos os casos a atividade química se encontra num valor abaixo de 1 , isso mostra que as condições de pressão e razão de $\mathrm{H}_{2} / \mathrm{CO}$ são ideais para evitar o depósito de carbono sólido no catalisador a qualquer temperatura.

Também foi calculada a dependência da atividade química do carbono em relação à razão de entrada de $\mathrm{H}_{2} / \mathrm{CO}_{2}$ a uma pressão de $101325 \mathrm{~Pa}$ e 300 ${ }^{\circ} \mathrm{C}$, para isso foi variada a concentração de $\mathrm{CO}_{2}$, e o resultado pode ser visto na Figura 7. 


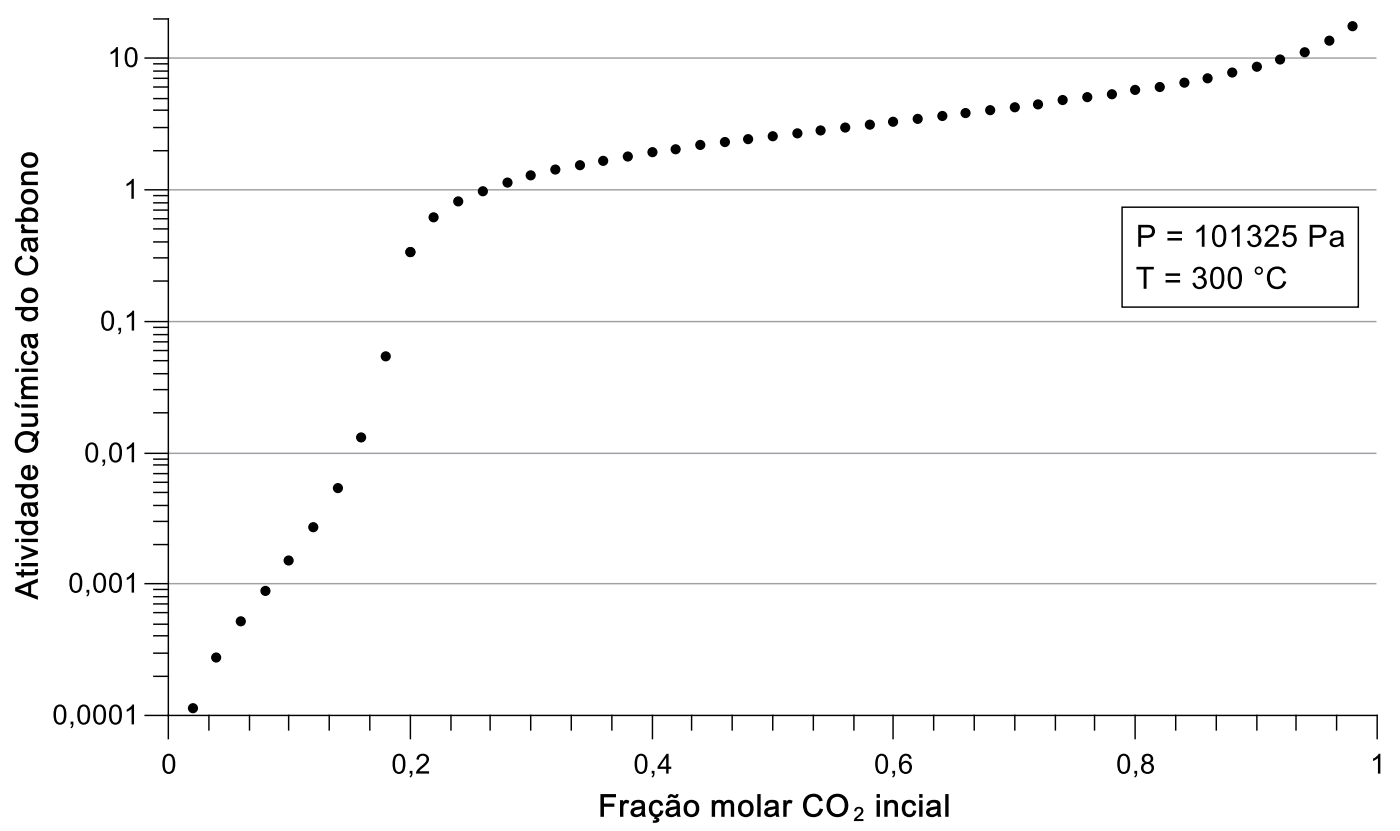

Figura 7 - Atividade química do carbono para diferentes concentrações de $\mathrm{CO}_{2}$.

Podemos notar que o comportamento foi diferente do estudado no caso da temperatura. Quando a razão de $\mathrm{H}_{2} / \mathrm{CO}_{2}$ é variada, existem valores para os quais a atividade química do carbono é maior do que 1, isso significa que essa razão deve ser escolhida com cuidado para garantir o bom funcionamento do catalisador, pode-se notar também que para a razão de 4 (fração molar de $\left.\mathrm{CO}_{2}=0,2\right)$, que foi escolhida ao longo dos cálculos como ideal, possui a atividade química do carbono menor que 1 , o que apenas reforça a escolha dessa razão como ideal.

\section{2.}

\section{Formação da acetona}

\subsection{1.}

\section{Cálculo do equilíbrio inicial}

Este cálculo teve como objetivo considerar o equilíbrio final do sistema estudando apenas a termodinâmica. Como ponto de partida foi empregada a equação química abaixo: 


$$
2 \mathrm{C}_{2} \mathrm{H}_{5} \mathrm{OH}+\mathrm{H}_{2} \mathrm{O} \rightarrow \mathrm{CH}_{3} \mathrm{COCH}_{3}+4 \mathrm{H}_{2}+\mathrm{CO}_{2}
$$

Como valores iniciais, foram empregados os valores experimentais de Silva-Calpa (8): 91 mol de $\mathrm{N}_{2}$ como gás inerte para a reação, $8 \mathrm{~mol}$ de $\mathrm{H}_{2} \mathrm{O}$ e 1 mol de etanol, a pressão atmosférica padrão e $400{ }^{\circ} \mathrm{C}$. Apesar de na composição inicial terem sido consideradas as espécies químicas, o programa Thermo-Calc considera apenas os átomos como entrada. As espécies químicas encontradas em quantidades maiores que a acetona se encontram na Tabela 1.

Tabela 1 - Componentes presentes no equilíbrio.

\begin{tabular}{|c|c|c|}
\hline Componente & Fração Molar (gas) & № Mol \\
\hline N2 & 8.86E-01 & $9.10 E+01$ \\
\hline $\mathrm{H} 2 \mathrm{O} 1$ & 6.13E-02 & $6.30 \mathrm{E}+00$ \\
\hline $\mathrm{H} 2$ & 3.35E-02 & $3.45 \mathrm{E}+00$ \\
\hline $\mathrm{C} 102$ & 1.29E-02 & $1.32 E+00$ \\
\hline $\mathrm{C} 1 \mathrm{H} 4$ & 6.04E-03 & $6.20 \mathrm{E}-01$ \\
\hline $\mathrm{C} 101$ & $5.76 \mathrm{E}-04$ & $5.92 \mathrm{E}-02$ \\
\hline $\mathrm{H} 3 \mathrm{~N} 1$ & 7.91E-05 & 8.13E-03 \\
\hline $\mathrm{C} 2 \mathrm{H} 6$ & 2.98E-09 & 3.06E-07 \\
\hline C1H1N1_HCN & $2.15 \mathrm{E}-10$ & $2.21 \mathrm{E}-08$ \\
\hline $\mathrm{C} 1 \mathrm{H} 2 \mathrm{O} 2 \_\mathrm{CIS}$ & $1.91 \mathrm{E}-10$ & 1.97E-08 \\
\hline $\mathrm{C} 1 \mathrm{H} 2 \mathrm{O} 1$ & $1.49 \mathrm{E}-11$ & 1.53E-09 \\
\hline $\mathrm{C} 1 \mathrm{H} 2 \mathrm{O} 2 \_T R A N S$ & $1.05 \mathrm{E}-11$ & $1.08 \mathrm{E}-09$ \\
\hline $\mathrm{C} 1 \mathrm{H} 4 \mathrm{O} 1$ & 8.32E-12 & $8.55 \mathrm{E}-10$ \\
\hline $\mathrm{C} 1 \mathrm{H} 1 \mathrm{~N} 1 \mathrm{O} 1$ & 8.11E-12 & 8.33E-10 \\
\hline $\mathrm{C} 2 \mathrm{H} 4$ & $7.78 \mathrm{E}-12$ & $7.99 \mathrm{E}-10$ \\
\hline C2H4O2_ACETI & $9.63 E-14$ & $9.89 \mathrm{E}-12$ \\
\hline C2H4O1_ACETA & 4.83E-14 & 4.96E-12 \\
\hline $\mathrm{C} 3 \mathrm{H} 8$ & $8.49 \mathrm{E}-15$ & $8.72 \mathrm{E}-13$ \\
\hline C1H1N1_HNC & $5.20 \mathrm{E}-15$ & $5.35 \mathrm{E}-13$ \\
\hline $\mathrm{C} 1 \mathrm{H} 3$ & $2.44 \mathrm{E}-15$ & $2.51 \mathrm{E}-13$ \\
\hline $\mathrm{H}$ & $1.02 E-15$ & $1.04 \mathrm{E}-13$ \\
\hline $\mathrm{C} 3 \mathrm{H} 6 \_2$ & $4.20 \mathrm{E}-16$ & $4.32 \mathrm{E}-14$ \\
\hline $\mathrm{C} 3 \mathrm{H} 6$ & 4.09E-16 & $4.21 \mathrm{E}-14$ \\
\hline $\mathrm{C} 2 \mathrm{H} 6 \mathrm{O} 1$ & $3.26 \mathrm{E}-16$ & $3.35 \mathrm{E}-14$ \\
\hline $\mathrm{C} 3 \mathrm{H} 6 \mathrm{O} 1$ & $1.25 \mathrm{E}-17$ & $1.29 \mathrm{E}-15$ \\
\hline
\end{tabular}


Pode-se notar que a reação é altamente oxidativa ao se observar os produtos formados, também pode ser notado que os principais componentes formados foram $\mathrm{H}_{2}$ e $\mathrm{CO}_{2}$, o que mostra que o que ocorreu na verdade foi a reforma do etanol pela água. Como não foi constatada a presença de acetona nessas condições, também foi feita uma variação da temperatura, de $350{ }^{\circ} \mathrm{C}$ a $550 \stackrel{\circ}{ } \mathrm{C}$, para ver se seria formada a acetona nesse caso, o resultado se encontra na Tabela 2.

Tabela 2 - Quantidade de acetona formada.

\begin{tabular}{|c|c|c|c|}
\hline $\mathrm{T}$ & $\begin{array}{c}\text { Fração } \\
\text { molar }\left(\text { Gas, } \mathrm{N}_{2}\right)\end{array}$ & $\begin{array}{l}\text { Fração molar } \\
\left(\mathrm{Gas}, \mathrm{C}_{3} \mathrm{H}_{6} \mathrm{O}\right)\end{array}$ & $\begin{array}{l}\quad \mathrm{N}=\mathrm{mol} \\
\mathrm{C}_{3} \mathrm{H}_{6} \mathrm{O}\end{array}$ \\
\hline 35 & & & \\
\hline 0 & 8.91E-01 & $6.24 \mathrm{E}-18$ & 6.37E-16 \\
\hline 37 & & & \\
\hline 0 & 8.89E-01 & 8.94E-18 & $9.15 \mathrm{E}-16$ \\
\hline 39 & & & \\
\hline 0 & 8.87E-01 & $1.15 \mathrm{E}-17$ & $1.18 \mathrm{E}-15$ \\
\hline 41 & & & \\
\hline 0 & 8.84E-01 & $1.31 \mathrm{E}-17$ & $1.35 \mathrm{E}-15$ \\
\hline 43 & & & \\
\hline 0 & 8.82E-01 & $1.28 \mathrm{E}-17$ & $1.32 \mathrm{E}-15$ \\
\hline 45 & & & \\
\hline 0 & 8.80E-01 & $1.03 E-17$ & 1.07E-15 \\
\hline 47 & & & \\
\hline 0 & 8.78E-01 & 6.63E-18 & $6.87 \mathrm{E}-16$ \\
\hline 49 & & & \\
\hline 0 & 8.77E-01 & 3.36E-18 & $3.49 \mathrm{E}-16$ \\
\hline 51 & & & \\
\hline 0 & 8.76E-01 & $1.38 \mathrm{E}-18$ & $1.44 \mathrm{E}-16$ \\
\hline 53 & & & \\
\hline 0 & 8.76E-01 & 4.96E-19 & $5.15 \mathrm{E}-17$ \\
\hline 55 & & & \\
\hline 0 & 8.75E-01 & 1.66E-19 & 1.73E-17 \\
\hline
\end{tabular}

Ambos os resultados mostram que não ocorre formação significativa de acetona nessas condições, já que ocorre a combustão completa do etanol, produzindo apenas $\mathrm{CO}_{2}$ e água.

Essa combustão completa não foi observada nos resultados de SilvaCalpa (8) como pode ser visto na Figura 8, onde se vê claramente a formação da acetona utilizando diversos catalisadores, esses testes foram realizados a 400 ○C e pressão de $1 \mathrm{~atm}$. 


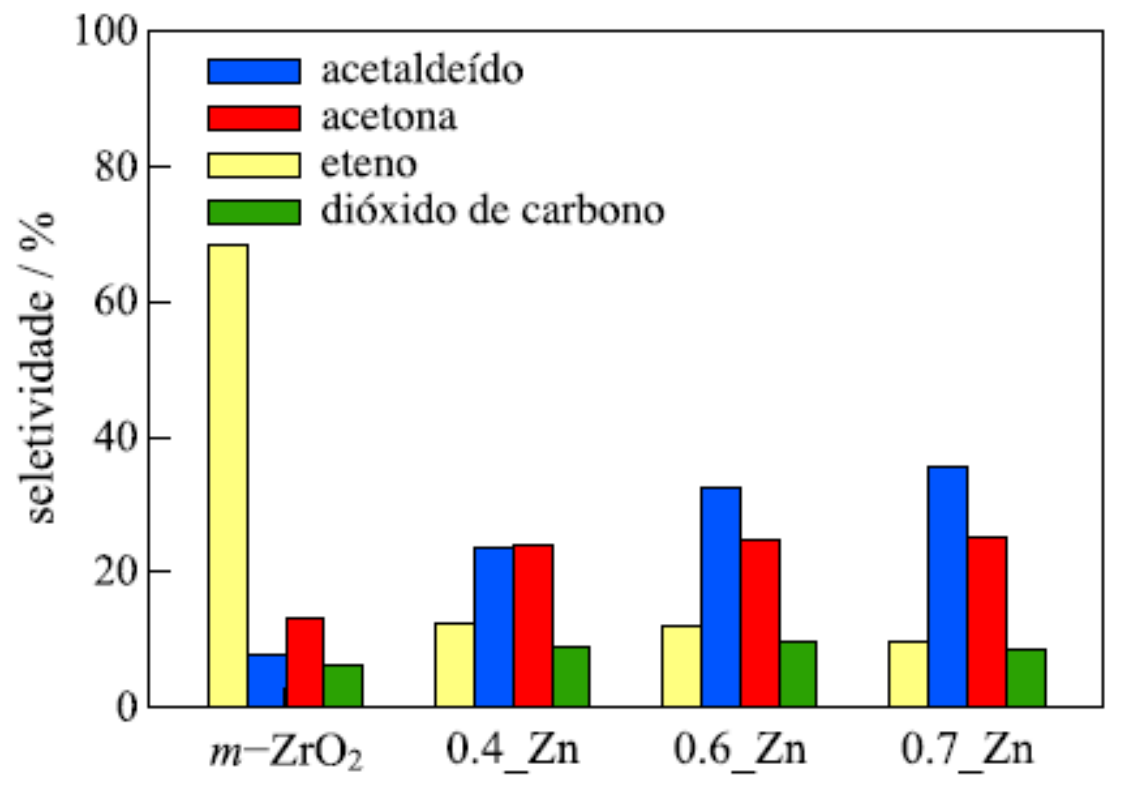

Figura 8 - Formação de acetona por diferentes catalisadores (8).

O motivo que pode ter levado a diferença tão significativa nesses resultados é a presença dos catalisadores. Isso mostra que nesse caso a função do catalisador não é apenas o de acelerar a reação, já que se fosse isso não haveria diferença na termodinâmica, mas de fato possibilitar a reação acontecer e, nesse caso particular, impedir a combustão total.

Os catalisadores também são responsáveis por modificar o mecanismo das reações, e cada um deles age de maneira diferente, por isso podem ser notados diferentes desempenhos nos testes de Silva-Calpa(8).

Para simular o efeito do catalisador, foram calculados equilíbrios metaestáveis dos gases, excluíndo a formação de algumas espécies químicas

\subsection{2.}

\section{Equilíbrios metaestáveis}

O equilíbrio foi calculado desconsiderando diversas espécies no banco de dados a temperatura constante, para descobrir em que condições a acetona começa a ser formada. Inicialmente foram desconsideradas as espécies presentes em maiores quantidades e as que poderiam sugerir uma combustão completa (como $0 \mathrm{CO}_{2}$ ). Também se optou por desconsiderar as espécies que contivessem nitrogênio na sua composição, já que $0 \quad N_{2}$ é um gás aproximadamente inerte em baixas temperaturas, ou seja, ele não irá reagir, e 
todo o nitrogênio continuará na forma de $\mathrm{N}_{2}$. As espécies desconsideradas inicialmente foram: $\mathrm{CO}_{2}, \mathrm{CO}, \mathrm{CH}_{4}$ e $\mathrm{H}_{3} \mathrm{~N}$. E o equilíbrio calculado se encontra na Tabela 3

Tabela 3 - Componentes encontrados no equilíbrio metaestável.

\begin{tabular}{ccc}
\hline Componente & Fração molar (gas) & № mol \\
\hline N2 & $8.98 \mathrm{E}-01$ & $9.10 \mathrm{E}+01$ \\
\hline $\mathrm{H} 2 \mathrm{O} 1$ & $8.88 \mathrm{E}-02$ & $9.00 \mathrm{E}+00$ \\
\hline $\mathrm{H} 2$ & $9.41 \mathrm{E}-03$ & $9.53 \mathrm{E}-01$ \\
\hline C6H6 & $2.51 \mathrm{E}-03$ & $2.54 \mathrm{E}-01$ \\
\hline C2H6 & $9.27 \mathrm{E}-04$ & $9.39 \mathrm{E}-02$ \\
\hline C60 & $4.66 \mathrm{E}-05$ & $4.72 \mathrm{E}-03$ \\
\hline C2H4 & $8.64 \mathrm{E}-06$ & $8.75 \mathrm{E}-04$ \\
\hline C1H2O2_ClS & $5.38 \mathrm{E}-06$ & $5.45 \mathrm{E}-04$ \\
\hline C2H4O2_ACETI & $2.85 \mathrm{E}-06$ & $2.89 \mathrm{E}-04$ \\
\hline C3H8 & $2.79 \mathrm{E}-06$ & $2.82 \mathrm{E}-04$ \\
\hline C3H6_2 & $4.92 \mathrm{E}-07$ & $4.98 \mathrm{E}-05$ \\
\hline C3H6 & $4.79 \mathrm{E}-07$ & $4.86 \mathrm{E}-05$ \\
\hline C1H1N1_HCN & $4.31 \mathrm{E}-07$ & $4.37 \mathrm{E}-05$ \\
\hline C1H2O2_TRANS & $2.95 \mathrm{E}-07$ & $2.98 \mathrm{E}-05$ \\
\hline C2H4O1_ACETA & $2.77 \mathrm{E}-07$ & $2.80 \mathrm{E}-05$ \\
\hline C6H6O1 & $1.28 \mathrm{E}-07$ & $1.29 \mathrm{E}-05$ \\
\hline C1H1N1O1 & $8.39 \mathrm{E}-08$ & $8.50 \mathrm{E}-06$ \\
\hline C1H2O1 & $8.09 \mathrm{E}-08$ & $8.20 \mathrm{E}-06$ \\
\hline C3H6O1 & $7.57 \mathrm{E}-08$ & $7.67 \mathrm{E}-06$ \\
\hline
\end{tabular}

Com esses cálculos se obteve um aumento na produção da acetona, mas mesmo assim, o resultado ainda está bem a abaixo do obtido experimentalmente. Por isso foram calculados diversos outros equilíbrios para tentar obter uma produção de acetona mais próxima da observado experimentalmente. As espécies desconsideradas em cada teste foram determinadas a partir dos resultados dos testes anteriores, escolhendo as que estavam sendo formadas em maiores quantidades que a acetona. Na Tabela 4 se encontram as concentrações de acetona e a sua seletividade em cada teste. 
Tabela 4 - Seletividade da acetona em diferentes equilíbrios metaestáveis.

\begin{tabular}{ccccc}
\hline Teste & $\begin{array}{c}\text { Fração } \\
\left.\text { molar ( } \mathrm{N}_{2}\right)\end{array}$ & $\begin{array}{c}\text { Fração } \\
\text { molar }\left(\mathrm{C}_{3} \mathrm{H}_{6} \mathrm{O}\right)\end{array}$ & $\begin{array}{c}\mathrm{N} \text { o mol } \\
\mathrm{C}_{3} \mathrm{H}_{6} \mathrm{O}\end{array}$ & Seletividade \\
\hline 3 & $9.05 \mathrm{E}-01$ & $3.05 \mathrm{E}-06$ & $3.06 \mathrm{E}-04$ & $0 \%$ \\
\hline 4 & $9.06 \mathrm{E}-01$ & $9.27 \mathrm{E}-06$ & $9.31 \mathrm{E}-04$ & $0 \%$ \\
\hline 5 & $9.06 \mathrm{E}-01$ & $3.46 \mathrm{E}-05$ & $3.48 \mathrm{E}-03$ & $1 \%$ \\
\hline 6 & $9.07 \mathrm{E}-01$ & $4.16 \mathrm{E}-05$ & $4.17 \mathrm{E}-03$ & $1 \%$ \\
\hline 7 & $9.07 \mathrm{E}-01$ & $1.78 \mathrm{E}-03$ & $1.79 \mathrm{E}-01$ & $27 \%$ \\
\hline 8 & $9.07 \mathrm{E}-01$ & $1.78 \mathrm{E}-03$ & $1.79 \mathrm{E}-01$ & $27 \%$ \\
\hline 9 & $9.07 \mathrm{E}-01$ & $1.78 \mathrm{E}-03$ & $1.79 \mathrm{E}-01$ & $27 \%$ \\
\hline 10 & $9.07 \mathrm{E}-01$ & $1.78 \mathrm{E}-03$ & $1.79 \mathrm{E}-01$ & $27 \%$ \\
\hline 11 & $9.01 \mathrm{E}-01$ & $3.01 \mathrm{E}-08$ & $3.04 \mathrm{E}-06$ & $0 \%$ \\
\hline 12 & $9.01 \mathrm{E}-01$ & $2.12 \mathrm{E}-17$ & $2.15 \mathrm{E}-15$ & $0 \%$ \\
\hline 13 & $9.04 \mathrm{E}-01$ & $6.86 \mathrm{E}-11$ & $6.90 \mathrm{E}-09$ & $0 \%$ \\
\hline 14 & $9.05 \mathrm{E}-01$ & $1.12 \mathrm{E}-08$ & $1.13 \mathrm{E}-06$ & $0 \%$ \\
\hline 15 & $8.87 \mathrm{E}-01$ & $6.24 \mathrm{E}-05$ & $6.40 \mathrm{E}-03$ & $1 \%$ \\
\hline
\end{tabular}

Em todos os testes as condições consideradas nos cálculos foram os empregados por Silva-Calpa (8) de 91 mol de $\mathrm{N}_{2}$ como inerte para a reação, 8 mol de $\mathrm{H}_{2} \mathrm{O}$ e $1 \mathrm{~mol}$ de etanol, a pressão atmosférica e $400^{\circ} \mathrm{C}$. A seletividade foi calculada considerando o número total de átomos de carbono no sistema que foram convertidos em acetona. As espécies desconsideradas em cada um dos testes podem ser vistas a seguir:

- Teste 3: Espécies desconsideradas: $\mathrm{CO}_{2}, \mathrm{CO}, \mathrm{CH}_{4}, \mathrm{H}_{3} \mathrm{~N}, \mathrm{H}_{2}, \mathrm{C}_{6} \mathrm{H}_{6}, \mathrm{C}_{2} \mathrm{H}_{6}$;

- Teste 4: Espécies desconsideradas: $\mathrm{CO}_{2}, \mathrm{CO}, \mathrm{CH}_{4}, \mathrm{H}_{3} \mathrm{~N}, \mathrm{H}_{2}, \mathrm{C}_{6} \mathrm{H}_{6}, \mathrm{C}_{2} \mathrm{H}_{6}$, $\mathrm{C}_{3} \mathrm{H}_{8}, \mathrm{C}_{2} \mathrm{H}_{4}, \mathrm{C}_{3} \mathrm{H}_{6} \_2$ (propeno);

- Teste 5: Espécies desconsideradas: $\mathrm{CO}_{2}, \mathrm{CO}, \mathrm{CH}_{4}, \mathrm{H}_{3} \mathrm{~N}, \mathrm{H}_{2}, \mathrm{C}_{6} \mathrm{H}_{6}, \mathrm{C}_{2} \mathrm{H}_{6}$, $\mathrm{C}_{3} \mathrm{H}_{8}, \mathrm{C}_{2} \mathrm{H}_{4}, \mathrm{C}_{3} \mathrm{H}_{6} \_$(propeno), $\mathrm{C}_{4} \mathrm{H}_{10}{ }_{1}$ (butano), $\mathrm{C}_{60}, \mathrm{C}_{4} \mathrm{H}_{8} 5$ (2metilpropeno); 
- Teste 6: Espécies desconsideradas: $\mathrm{CO}_{2}, \mathrm{CO}, \mathrm{CH}_{4}, \mathrm{H}_{3} \mathrm{~N}, \mathrm{H}_{2}, \mathrm{C}_{6} \mathrm{H}_{6}, \mathrm{C}_{2} \mathrm{H}_{6}$, $\mathrm{C}_{3} \mathrm{H}_{8}, \mathrm{C}_{2} \mathrm{H}_{4}, \mathrm{C}_{3} \mathrm{H}_{6} \_2$ (propeno), $\mathrm{C}_{4} \mathrm{H}_{10}{ }_{1}$ (butano), $\mathrm{C}_{60}, \mathrm{C}_{4} \mathrm{H}_{8} \_$(2metilpropeno), $\mathrm{C}_{3} \mathrm{H}_{6}, \mathrm{C}_{4} \mathrm{H}_{8} 3$ (trans-2-buteno), $\mathrm{C}_{4} \mathrm{H}_{8} 2$ (cis-2-buteno), $\mathrm{C}_{4} \mathrm{H}_{8} 1$ (1-buteno), $\mathrm{CHN}-\mathrm{HCN}$ (cianeto de hidrogênio);

- Teste 7: Espécies desconsideradas: $\mathrm{CO}_{2}, \mathrm{CO}, \mathrm{CH}_{4}, \mathrm{H}_{3} \mathrm{~N}, \mathrm{H}_{2}, \mathrm{C}_{6} \mathrm{H}_{6}, \mathrm{C}_{2} \mathrm{H}_{6}$, $\mathrm{C}_{3} \mathrm{H}_{8}, \mathrm{C}_{2} \mathrm{H}_{4}, \mathrm{C}_{3} \mathrm{H}_{6 \_} 2$ (propeno), $\mathrm{C}_{4} \mathrm{H}_{10} 1$ (butano), $\mathrm{C}_{60}, \mathrm{C}_{4} \mathrm{H}_{8-} 5$ (2metilpropeno), $\mathrm{C}_{3} \mathrm{H}_{6}, \mathrm{C}_{4} \mathrm{H}_{8} 3$ (trans-2-buteno), $\mathrm{C}_{4} \mathrm{H}_{8} \_$(cis-2-buteno), $\mathrm{C}_{4} \mathrm{H}_{8} 1$ (1-buteno), $\mathrm{CHN}-\mathrm{HCN}$ (cianeto de hidrogênio), $\mathrm{C}_{4} \mathrm{H}_{8}$ (ciclobutano), $\mathrm{C}_{4} \mathrm{H}_{6} \_$2 (1,3-butadieno);

- Teste 8: Espécies desconsideradas: $\mathrm{CH}_{4}, \mathrm{H}_{3} \mathrm{~N}, \mathrm{H}_{2}, \mathrm{C}_{6} \mathrm{H}_{6}, \mathrm{C}_{2} \mathrm{H}_{6}, \mathrm{C}_{3} \mathrm{H}_{8}$, $\mathrm{C}_{2} \mathrm{H}_{4}, \mathrm{C}_{3} \mathrm{H}_{6} 2$ (propeno), $\mathrm{C}_{4} \mathrm{H}_{10} \_1$ (butano), $\mathrm{C}_{60}, \mathrm{C}_{4} \mathrm{H}_{8} 5$ (2-metilpropeno), $\mathrm{C}_{3} \mathrm{H}_{6}, \mathrm{C}_{4} \mathrm{H}_{8} 3$ (trans-2-buteno), $\mathrm{C}_{4} \mathrm{H}_{8} \_2$ (cis-2-buteno), $\mathrm{C}_{4} \mathrm{H}_{8} \_1$ (1-buteno), $\mathrm{CHN}-\mathrm{HCN}$ (cianeto de hidrogênio), $\mathrm{C}_{4} \mathrm{H}_{8}$ (ciclobutano), $\mathrm{C}_{4} \mathrm{H}_{6} \_2$ (1,3butadieno), $\mathrm{C}_{4} \mathrm{H}_{10 \_} 2$ (isobutano);

- Teste 9: Espécies desconsideradas: $\mathrm{CO}, \mathrm{CH}_{4}, \mathrm{H}_{3} \mathrm{~N}, \mathrm{H}_{2}, \mathrm{C}_{6} \mathrm{H}_{6}, \mathrm{C}_{2} \mathrm{H}_{6}, \mathrm{C}_{3} \mathrm{H}_{8}$, $\mathrm{C}_{2} \mathrm{H}_{4}, \mathrm{C}_{3} \mathrm{H}_{6} 2$ (propeno), $\mathrm{C}_{4} \mathrm{H}_{10}{ }_{1} 1$ (butano), $\mathrm{C}_{60}, \mathrm{C}_{4} \mathrm{H}_{8} 5$ (2-metilpropeno), $\mathrm{C}_{3} \mathrm{H}_{6}, \mathrm{C}_{4} \mathrm{H}_{8} 3$ (trans-2-buteno), $\mathrm{C}_{4} \mathrm{H}_{8} 2$ 2 (cis-2-buteno), $\mathrm{C}_{4} \mathrm{H}_{8} \_1$ (1-buteno), $\mathrm{CHN}-\mathrm{HCN}$ (cianeto de hidrogênio), $\mathrm{C}_{4} \mathrm{H}_{8}$ (ciclobutano), $\mathrm{C}_{4} \mathrm{H}_{6} \_2$ (1,3butadieno) $\mathrm{C}_{4} \mathrm{H}_{10 \_} 2$ (isobutano);

- Teste 10: Espécies desconsideradas: $\mathrm{CO}_{2}, \mathrm{CH}_{4}, \mathrm{H}_{3} \mathrm{~N}, \mathrm{H}_{2}, \mathrm{C}_{6} \mathrm{H}_{6}, \mathrm{C}_{2} \mathrm{H}_{6}$, $\mathrm{C}_{3} \mathrm{H}_{8}, \mathrm{C}_{2} \mathrm{H}_{4}, \mathrm{C}_{3} \mathrm{H}_{6} 2$ (propeno), $\mathrm{C}_{4} \mathrm{H}_{10 \_} 1$ (butano), $\mathrm{C}_{60}, \mathrm{C}_{4} \mathrm{H}_{8} 5$ (2metilpropeno), $\mathrm{C}_{3} \mathrm{H}_{6}, \mathrm{C}_{4} \mathrm{H}_{8} \_3$ (trans-2-buteno), $\mathrm{C}_{4} \mathrm{H}_{8} 2$ (cis-2-buteno), $\mathrm{C}_{4} \mathrm{H}_{8} 1$ (1-buteno), $\mathrm{CHN}-\mathrm{HCN}$ (cianeto de hidrogênio), $\mathrm{C}_{4} \mathrm{H}_{8}$ (ciclobutano), $\mathrm{C}_{4} \mathrm{H}_{6} \_2$ (1,3-butadieno) $\mathrm{C}_{4} \mathrm{H}_{10 \_} 2$ (isobutano);

- Teste 11: Espécies desconsideradas: $\mathrm{CH}_{4}, \mathrm{H}_{3} \mathrm{~N}, \mathrm{H}_{2}, \mathrm{C}_{6} \mathrm{H}_{6}, \mathrm{C}_{2} \mathrm{H}_{6}, \mathrm{C}_{3} \mathrm{H}_{8}$, $\mathrm{C}_{3} \mathrm{H}_{6} 2$ (propeno), $\mathrm{C}_{4} \mathrm{H}_{10}{ }_{1}$ (butano), $\mathrm{C}_{60}, \mathrm{C}_{4} \mathrm{H}_{8} 5$ (2-metilpropeno), $\mathrm{C}_{3} \mathrm{H}_{6}$, $\mathrm{C}_{4} \mathrm{H}_{8} 3$ (trans-2-buteno), $\mathrm{C}_{4} \mathrm{H}_{8} 2$ (cis-2-buteno), $\mathrm{C}_{4} \mathrm{H}_{8}$ 1 (1-buteno), $\mathrm{CHN}$ $\mathrm{HCN}$ (cianeto de hidrogênio), $\mathrm{C}_{4} \mathrm{H}_{8}$ (ciclobutano), $\mathrm{C}_{4} \mathrm{H}_{6} \_$(1,3-butadieno) $\mathrm{C}_{4} \mathrm{H}_{10 \_} 2$ (isobutano);

- Teste 12: Espécies desconsideradas: $\mathrm{H}_{3} \mathrm{~N}, \mathrm{H}_{2}, \mathrm{C}_{6} \mathrm{H}_{6}, \mathrm{C}_{2} \mathrm{H}_{6}, \mathrm{C}_{3} \mathrm{H}_{8}, \mathrm{C}_{3} \mathrm{H}_{6} 2$ (propeno), $\mathrm{C}_{4} \mathrm{H}_{10 \_} 1$ (butano), $\mathrm{C}_{60}, \mathrm{C}_{4} \mathrm{H}_{8} 5$ (2-metilpropeno), $\mathrm{C}_{3} \mathrm{H}_{6}, \mathrm{C}_{4} \mathrm{H}_{8} 3$ (trans-2-buteno), $\mathrm{C}_{4} \mathrm{H}_{8} 2$ (cis-2-buteno), $\mathrm{C}_{4} \mathrm{H}_{8} 1$ ( (1-buteno), $\mathrm{CHN}-\mathrm{HCN}$ (cianeto de hidrogênio), $\mathrm{C}_{4} \mathrm{H}_{8}$ (ciclobutano), $\mathrm{C}_{4} \mathrm{H}_{6}{ }_{2}$ (1,3-butadieno) $\mathrm{C}_{4} \mathrm{H}_{10 \_} 2$ (isobutano), $\mathrm{C}_{2} \mathrm{H}_{4}$;

- Teste 13: Espécies desconsideradas: $\mathrm{H}_{3} \mathrm{~N}, \mathrm{H}_{2}, \mathrm{C}_{6} \mathrm{H}_{6}, \mathrm{CH}_{4}, \mathrm{C}_{3} \mathrm{H}_{8}, \mathrm{C}_{3} \mathrm{H}_{6} 2$ (propeno), $\mathrm{C}_{4} \mathrm{H}_{10}{ }_{1}$ (butano), $\mathrm{C}_{60}, \mathrm{C}_{4} \mathrm{H}_{8} 5$ (2-metilpropeno), $\mathrm{C}_{3} \mathrm{H}_{6}, \mathrm{C}_{4} \mathrm{H}_{8} 3$ (trans-2-buteno), $\mathrm{C}_{4} \mathrm{H}_{8} 2$ 2 (cis-2-buteno), $\mathrm{C}_{4} \mathrm{H}_{8} 1$ 1 (1-buteno), $\mathrm{CHN}-\mathrm{HCN}$ (cianeto de hidrogênio), $\mathrm{C}_{4} \mathrm{H}_{8}$ (ciclobutano), $\mathrm{C}_{4} \mathrm{H}_{6} 2$ 2 (1,3-butadieno) $\mathrm{C}_{4} \mathrm{H}_{10 \_} 2$ (isobutano), $\mathrm{C}_{2} \mathrm{H}_{4}$;

- Teste 14: Espécies desconsideradas: $\mathrm{CH}_{4}, \mathrm{H}_{3} \mathrm{~N}, \mathrm{H}_{2}, \mathrm{C}_{6} \mathrm{H}_{6}, \mathrm{C}_{2} \mathrm{H}_{6}, \mathrm{C}_{3} \mathrm{H}_{8}$, $\mathrm{C}_{3} \mathrm{H}_{6 \_} 2$ (propeno), $\mathrm{C}_{4} \mathrm{H}_{10 \_} 1$ (butano), $\mathrm{C}_{4} \mathrm{H}_{10 \_} 2$ (isobutano), $\mathrm{C}_{60}, \mathrm{C}_{3} \mathrm{H}_{6}$, 
CHN-HCN (cianeto de hidrogênio), $\mathrm{C}_{4} \mathrm{H}_{6 \_} 2$ (1,3-butadieno), $\mathrm{C}_{2} \mathrm{H}_{4}$;

- Teste 15: Espécies desconsideradas: $\mathrm{CH}_{4}, \mathrm{H}_{2}, \mathrm{C}_{6} \mathrm{H}_{6}, \mathrm{C}_{2} \mathrm{H}_{6}, \mathrm{C}_{3} \mathrm{H}_{8}, \mathrm{C}_{3} \mathrm{H}_{6} 2$ (propeno), $\mathrm{C}_{4} \mathrm{H}_{10}{ }_{1} 1$ (butano), $\mathrm{C}_{4} \mathrm{H}_{10} 22$ (isobutano), $\mathrm{C}_{60}, \mathrm{C}_{3} \mathrm{H}_{6}, \mathrm{C}_{4} \mathrm{H}_{6} 2$ (1,3-butadieno), $\mathrm{C}_{2} \mathrm{H}_{4}, \mathrm{C}_{4} \mathrm{H}_{8} \_$(2-metilpropeno), $\mathrm{C}_{3} \mathrm{H}_{6}, \mathrm{C}_{4} \mathrm{H}_{8} 3$ (trans-2buteno), $\mathrm{C}_{4} \mathrm{H}_{8} 2$ (cis-2-buteno), $\mathrm{C}_{4} \mathrm{H}_{8} 1$ (1-buteno), $\mathrm{C}_{4} \mathrm{H}_{8}$ (ciclobutano);

Sabendo o que foi desconsiderado em cada um dos testes é possível identificar qual deles obteve resultados mais satisfatórios. Claramente até o Teste 6 não foram obtidos resultados satisfatórios como pode ser visto observando os resultados da seletividade da acetona, isso mostra que ainda existem outras espécies que estão sendo formadas antes.

No Teste 7 já se observam bons resultados na seletividade, mas ainda havia o interesse em continuar realizando os cálculos com diferentes espécies rejeitadas, no Teste 8 foi considerado que poderia haver a formação tanto de $\mathrm{CO}$ quanto de $\mathrm{CO}_{2}$ para ver o quanto isso afetaria a seletividade. Foi notado que não houve diferença, e como essas espécies foram encontradas por Silva-Calpa (8), o teste 8 foi considerado como um melhor resultado.

Nos Testes 9 e 10 também foram obtidos resultados satisfatórios para a seletividade, as espécies rejeitadas foram similares às do Teste 8 , mas ao invés de considerar a formação tanto de $\mathrm{CO}$ quanto de $\mathrm{CO}_{2}$ foi considerado apenas um deles em cada teste, no Teste 9 se considerou a formação de $\mathrm{CO}_{2}$ e no Teste 10 a formação de CO. Como os resultados continuaram sendo muito parecidos o Teste 8 continuou sendo considerado como o melhor resultado obtido. Assim sendo, pode-se propor que a presença de qualquer um desses dois gases não deve afetar a formação da acetona e, por isso, ambas as espécies foram consideradas presentes em todos os cálculos posteriores.

Como foi visto a adição de algumas espécies não modificou o resultado encontrado, então nos Testes 11, 12, 13, 14 e 15 foram consideradas mais espécies que nos testes anteriores, mas isso afetou drasticamente a seletividade da acetona, fazendo novamente com que ela não aparecesse nos resultados, por isso nenhum desses testes foi considerado e o Teste 8 continuou como o melhor resultado obtido e utilizado pelo resto do trabalho. As composições totais encontradas com frações maiores que $10^{-10}$ podem ser vistas na Tabela 5. 
Tabela 5 - Componentes encontrados no Teste 8.

\begin{tabular}{ccc}
\hline Componentes & Fração molar (gás) & No mol \\
\hline N2 & $9.07 \mathrm{E}-01$ & $9.10 \mathrm{E}+01$ \\
\hline $\mathrm{H} 2 \mathrm{O} 1$ & $8.43 \mathrm{E}-02$ & $8.46 \mathrm{E}+00$ \\
\hline$-\mathrm{CH} 2 \mathrm{CH} 3$ & $3.64 \mathrm{E}-03$ & $3.65 \mathrm{E}-01$ \\
\hline C2H6O1 & $3.55 \mathrm{E}-03$ & $3.57 \mathrm{E}-01$ \\
\hline C3H6O1 & $1.78 \mathrm{E}-03$ & $1.79 \mathrm{E}-01$ \\
\hline C1H4O1 & $3.22 \mathrm{E}-05$ & $3.23 \mathrm{E}-03$ \\
\hline C4H6_4 & $2.83 \mathrm{E}-05$ & $2.84 \mathrm{E}-03$ \\
\hline C4H6_1 & $5.93 \mathrm{E}-06$ & $5.95 \mathrm{E}-04$ \\
\hline -CH3 & $3.18 \mathrm{E}-06$ & $3.19 \mathrm{E}-04$ \\
\hline C4H6_3 & $2.78 \mathrm{E}-06$ & $2.79 \mathrm{E}-04$ \\
\hline C2H4O1_ACETA & $2.43 \mathrm{E}-06$ & $2.44 \mathrm{E}-04$ \\
\hline C4H6_5 & $2.75 \mathrm{E}-07$ & $2.76 \mathrm{E}-05$ \\
\hline C3H4_2 & $2.69 \mathrm{E}-07$ & $2.70 \mathrm{E}-05$ \\
\hline C3H4_1 & $4.82 \mathrm{E}-08$ & $4.84 \mathrm{E}-06$ \\
\hline C101 & $4.77 \mathrm{E}-08$ & $4.78 \mathrm{E}-06$ \\
\hline & &
\end{tabular}

\subsection{3.}

\section{Influência da razão etanol/água e da temperatura no equilíbrio} metastável

A Tabela 6 apresenta a influência da temperatura e da razão etanol/água na conversão de etanol nos equilíbrios. Essa conversão foi calculada diminuindo o número de mol inicialmente no sistema do número de mol encontrados ao final do cálculo de equilíbrio, esse valor encontrado foi dividido pelo número de mol iniciais para se chegar na conversão. Todos esses equilíbrios foram calculados a pressão de $101325 \mathrm{~Pa}$ e número total de mol igual a 100, sendo $91 \mathrm{~mol}$ de $\mathrm{N}_{2}$ inerte. 
Tabela 6 - Conversão de etanol.

\begin{tabular}{r|rrrrrrrr}
\cline { 2 - 9 } & \multicolumn{7}{c}{ Conversão de Etanol } \\
\cline { 2 - 10 } $\mathrm{T}\left({ }^{\circ} \mathrm{C}\right)$ & 0,125 & 0,286 & 0,500 & 0,800 & 1,25 & 2,00 & 3,50 & 8,00 \\
\hline 300 & $18,6 \%$ & $21,7 \%$ & $24,5 \%$ & $27,3 \%$ & $30,2 \%$ & $33,2 \%$ & $36,4 \%$ & $39,8 \%$ \\
325 & $29,3 \%$ & $33,3 \%$ & $36,5 \%$ & $39,5 \%$ & $42,3 \%$ & $45,2 \%$ & $48,1 \%$ & $50,9 \%$ \\
350 & $41,5 \%$ & $45,7 \%$ & $48,9 \%$ & $51,7 \%$ & $54,3 \%$ & $56,7 \%$ & $59,1 \%$ & $61,3 \%$ \\
375 & $53,6 \%$ & $57,6 \%$ & $60,4 \%$ & $62,8 \%$ & $64,9 \%$ & $66,9 \%$ & $68,7 \%$ & $70,4 \%$ \\
400 & $64,3 \%$ & $67,8 \%$ & $70,1 \%$ & $72,0 \%$ & $73,7 \%$ & $75,1 \%$ & $76,5 \%$ & $77,7 \%$ \\
425 & $73,1 \%$ & $76,0 \%$ & $77,8 \%$ & $79,3 \%$ & $80,5 \%$ & $81,6 \%$ & $82,6 \%$ & $83,4 \%$ \\
450 & $80,0 \%$ & $82,2 \%$ & $83,7 \%$ & $84,8 \%$ & $85,7 \%$ & $86,5 \%$ & $87,2 \%$ & $87,8 \%$ \\
475 & $85,2 \%$ & $86,9 \%$ & $88,1 \%$ & $88,9 \%$ & $89,6 \%$ & $90,1 \%$ & $90,6 \%$ & $91,1 \%$ \\
500 & $89,1 \%$ & $90,4 \%$ & $91,3 \%$ & $91,9 \%$ & $92,4 \%$ & $92,8 \%$ & $93,2 \%$ & $93,5 \%$
\end{tabular}

A conversão de etanol foi menor tanto em razões mais baixas quanto a temperaturas mais baixas, também é possível observar que o efeito da temperatura foi muito maior, ou seja aumentos pequenos de temperatura levam a grandes aumentos no consumo do etanol. É possível notar também que quanto mais a temperatura for aumentada, menor será o efeito da razão, até pelo fato de já se tratarem de conversões altas. Esses dados também foram representados no gráfico na Figura 9.

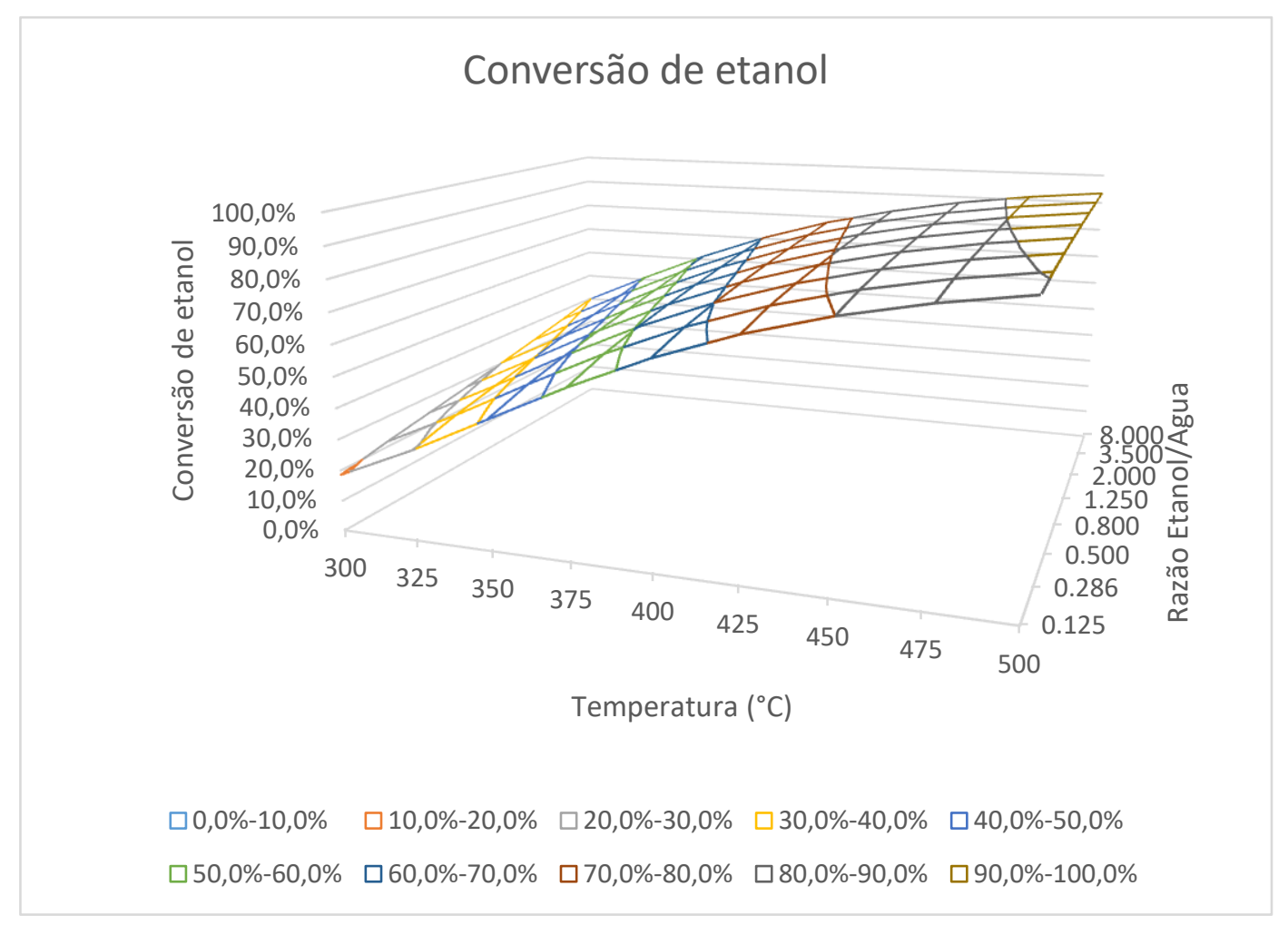

Figura 9 - Conversão de etanol. 
A Tabela 7 apresenta o número de mol de acetona formados nos equilíbrios apresentados na Tabela 6 , mas esse resultado não necessariamente representa quais condições são as ideais para essa reação. Para obter melhores resultados esses dados foram convertidos para seletividade, e se encontram na Tabela 8.

Tabela 7 - Quantidade molar de acetona

\begin{tabular}{r|rrrrrrrr}
\cline { 2 - 8 } & \multicolumn{7}{c}{ Mols de acetona } \\
\cline { 2 - 9 } $\mathrm{T}\left({ }^{\circ} \mathrm{C}\right)$ & 0,125 & 0,286 & 0,500 & 0,800 & 1,25 & 2,00 & 3,50 & 8,00 \\
\hline 300 & 0,05 & 0,12 & 0,21 & 0,31 & 0,43 & 0,57 & 0,72 & 0,90 \\
325 & 0,08 & 0,19 & 0,31 & 0,45 & 0,60 & 0,77 & 0,95 & 1,15 \\
350 & 0,12 & 0,26 & 0,41 & 0,58 & 0,76 & 0,95 & 1,15 & 1,36 \\
375 & 0,15 & 0,32 & 0,51 & 0,70 & 0,90 & 1,10 & 1,31 & 1,52 \\
400 & 0,18 & 0,37 & 0,57 & 0,78 & 0,99 & 1,19 & 1,40 & 1,61 \\
425 & 0,20 & 0,41 & 0,61 & 0,82 & 1,02 & 1,23 & 1,42 & 1,63 \\
450 & 0,21 & 0,42 & 0,62 & 0,82 & 1,01 & 1,20 & 1,38 & 1,55 \\
475 & 0,21 & 0,41 & 0,60 & 0,44 & 0,95 & 1,11 & 1,26 & 1,41 \\
500 & 0,20 & 0,38 & 0,26 & 0,70 & 0,85 & 0,98 & 1,11 & 1,23
\end{tabular}

Tabela 8 - Seletividade de acetona

\begin{tabular}{r|rrrrrrrr}
\cline { 2 - 9 } & \multicolumn{7}{c}{ Seletividade Acetona } \\
\cline { 2 - 9 } $\mathrm{T}\left({ }^{\circ} \mathrm{C}\right)$ & 0,125 & 0,286 & 0,500 & 0,800 & 1,250 & 2,00 & 3,50 & 8,00 \\
\hline 300 & $7,9 \%$ & $9,3 \%$ & $10,5 \%$ & $11,7 \%$ & $12,9 \%$ & $14,2 \%$ & $15,5 \%$ & $16,9 \%$ \\
325 & $12,5 \%$ & $14,2 \%$ & $15,5 \%$ & $16,8 \%$ & $18,0 \%$ & $19,2 \%$ & $20,3 \%$ & $21,5 \%$ \\
350 & $17,6 \%$ & $19,4 \%$ & $20,7 \%$ & $21,8 \%$ & $22,9 \%$ & $23,8 \%$ & $24,7 \%$ & $25,5 \%$ \\
375 & $22,6 \%$ & $24,2 \%$ & $25,3 \%$ & $26,1 \%$ & $26,9 \%$ & $27,5 \%$ & $28,0 \%$ & $28,5 \%$ \\
400 & $26,8 \%$ & $28,0 \%$ & $28,7 \%$ & $29,2 \%$ & $29,6 \%$ & $29,9 \%$ & $30,1 \%$ & $30,2 \%$ \\
425 & $29,8 \%$ & $30,4 \%$ & $30,7 \%$ & $30,7 \%$ & $30,7 \%$ & $30,7 \%$ & $30,5 \%$ & $30,5 \%$ \\
450 & $31,4 \%$ & $31,3 \%$ & $31,0 \%$ & $30,7 \%$ & $30,3 \%$ & $29,9 \%$ & $29,5 \%$ & $29,0 \%$ \\
475 & $31,5 \%$ & $30,7 \%$ & $29,9 \%$ & $29,1 \%$ & $28,4 \%$ & $27,7 \%$ & $27,1 \%$ & $26,4 \%$ \\
500 & $30,1 \%$ & $28,6 \%$ & $27,4 \%$ & $26,3 \%$ & $25,4 \%$ & $24,5 \%$ & $23,8 \%$ & $23,1 \%$
\end{tabular}


A seletividade da acetona é afetada tanto pela razão quanto pela temperatura. Para temperaturas baixas o aumento da razão sempre implica em um aumento na seletividade, o que levaria crer que uma razão maior sempre seria preferida. Mas em temperaturas mais altas a razão passa a não influenciar na seletividade, e chega até a ser prejudicial.

A maior seletividade encontrada foi de $31.5 \%$ a baixas razões de etanol/água e temperaturas altas de $475^{\circ} \mathrm{C}$, esses resultados são compatíveis com os encontrados por Silva-Calpa (8) para razão de etanol/água igual a 0.125 , que também observou altas seletividades (próximo a 40\%) a temperaturas elevadas (entre $425^{\circ} \mathrm{C}$ e $475^{\circ} \mathrm{C}$ ). Os resultados não são exatamente iguais por um se tratar de reações experimentais com catalisadores, e a dificuldade de representar esses catalisadores em cálculos termodinâmicos. Por exemplo, a presença de catalisadores pode reduzir a cinética mas ainda permitir a formação de espécies que afetam a formação da acetona.

Os dados da seletividade de acetona também podem ser vistos no gráfico na Figura 10.

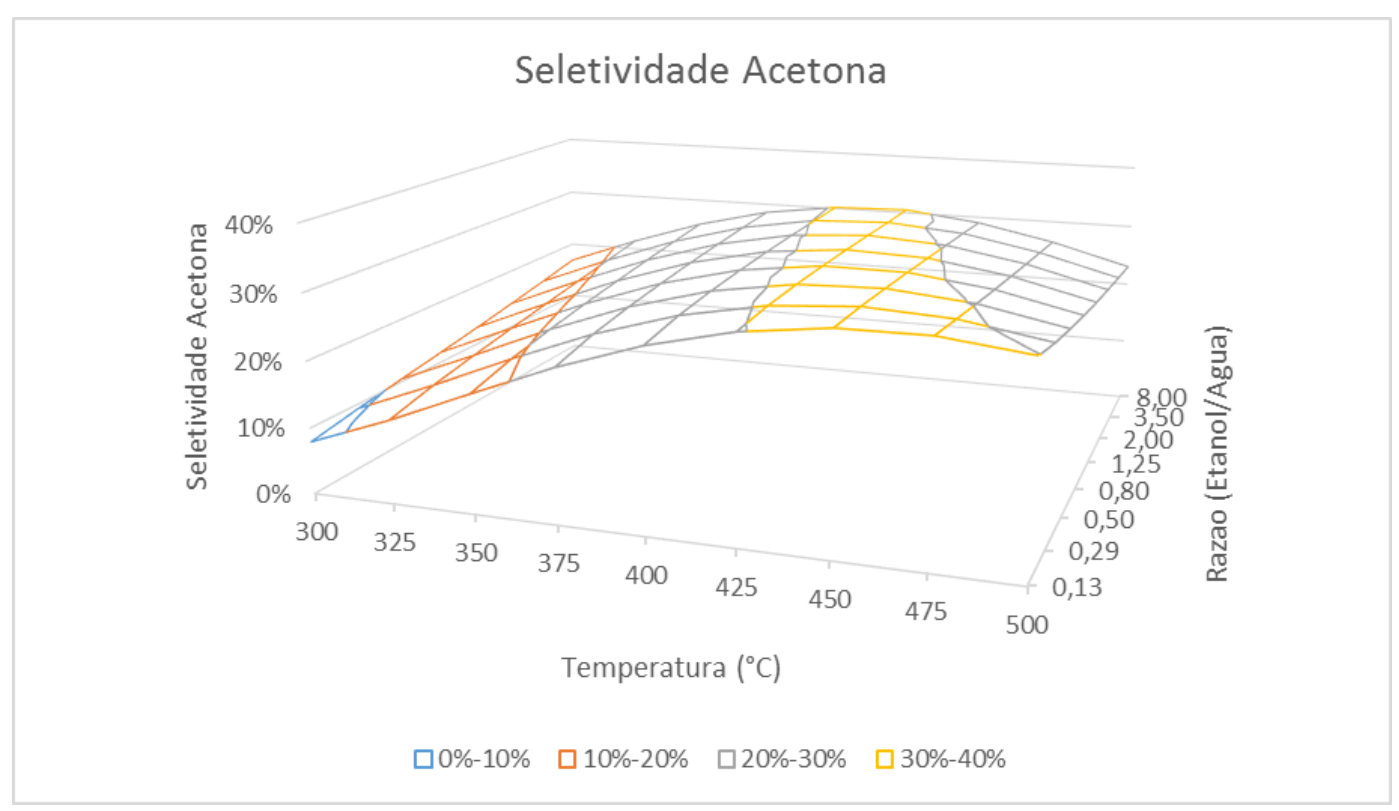

Figura 10 - Seletividade da Acetona.

\subsection{4.}

\section{Espécies relevantes encontradas}

Nos cálculos também foram notadas a presença de outras espécies em quantidades elevadas, na Tabela 9 podemos ver a seletividade do radical etil. 
Tabela 9 - Seletividade do etil

\begin{tabular}{r|rrrrrrrr}
\cline { 2 - 9 } & \multicolumn{7}{c}{ Seletividade Etil } \\
\cline { 2 - 9 } $\mathrm{T}\left({ }^{\circ} \mathrm{C}\right)$ & 0,125 & 0,286 & 0,500 & 0,800 & 1,25 & 2,00 & 3,50 & 8,00 \\
\hline 300 & $10,6 \%$ & $12,4 \%$ & $14,0 \%$ & $15,6 \%$ & $17,2 \%$ & $18,9 \%$ & $20,8 \%$ & $22,7 \%$ \\
325 & $16,7 \%$ & $19,0 \%$ & $20,8 \%$ & $22,5 \%$ & $24,2 \%$ & $25,8 \%$ & $27,4 \%$ & $29,0 \%$ \\
350 & $23,6 \%$ & $26,1 \%$ & $27,9 \%$ & $29,5 \%$ & $30,9 \%$ & $32,3 \%$ & $33,6 \%$ & $34,9 \%$ \\
375 & $30,5 \%$ & $32,8 \%$ & $34,4 \%$ & $35,7 \%$ & $36,9 \%$ & $38,0 \%$ & $39,0 \%$ & $39,9 \%$ \\
400 & $36,5 \%$ & $38,5 \%$ & $39,8 \%$ & $40,8 \%$ & $41,7 \%$ & $42,5 \%$ & $43,2 \%$ & $43,9 \%$ \\
425 & $41,4 \%$ & $43,0 \%$ & $44,0 \%$ & $44,7 \%$ & $45,4 \%$ & $45,9 \%$ & $46,4 \%$ & $47,0 \%$ \\
450 & $45,1 \%$ & $46,3 \%$ & $47,0 \%$ & $47,5 \%$ & $47,9 \%$ & $48,2 \%$ & $48,5 \%$ & $48,7 \%$ \\
475 & $47,8 \%$ & $48,5 \%$ & $49,0 \%$ & $49,3 \%$ & $49,5 \%$ & $49,7 \%$ & $49,8 \%$ & $49,9 \%$ \\
500 & $49,6 \%$ & $50,0 \%$ & $50,2 \%$ & $50,3 \%$ & $50,4 \%$ & $50,5 \%$ & $50,5 \%$ & $50,6 \%$
\end{tabular}

A seletividade do etil se comporta de maneira muito parecida com a conversão de etanol vista anteriormente. A baixas temperaturas ele aumenta junto com a razão etanol/água, mas quando se aumenta a temperatura a razão tem uma influência cada vez menor, o que mostra que a seletividade do etil é na sua maior parte determinada pela temperatura.

A seletividade do etil tem valores muito altos, chegando até a $50 \%$, esse resultado pode ser explicado pela formação da espécie etil estar atrelada a formação de $\mathrm{O}_{2}$, esse fornecimento de $\mathrm{O}_{2}$ para a reação normalmente seria feito pelo catalisador, como foi sugerido por Rodrigues (41). A reação de formação do etil foi sugerida na equação 36 .

$$
4 \mathrm{C}_{2} \mathrm{H}_{5} \mathrm{OH} \rightarrow 4 \mathrm{C}_{2} \mathrm{H}_{5}+2 \mathrm{H}_{2} \mathrm{O}+\mathrm{O}_{2}
$$

Isso também ajuda a explicar o porquê da quantidade de água encontrada no equilíbrio ser maior que a introduzida no sistema, já que ela é formada na equação 36. 


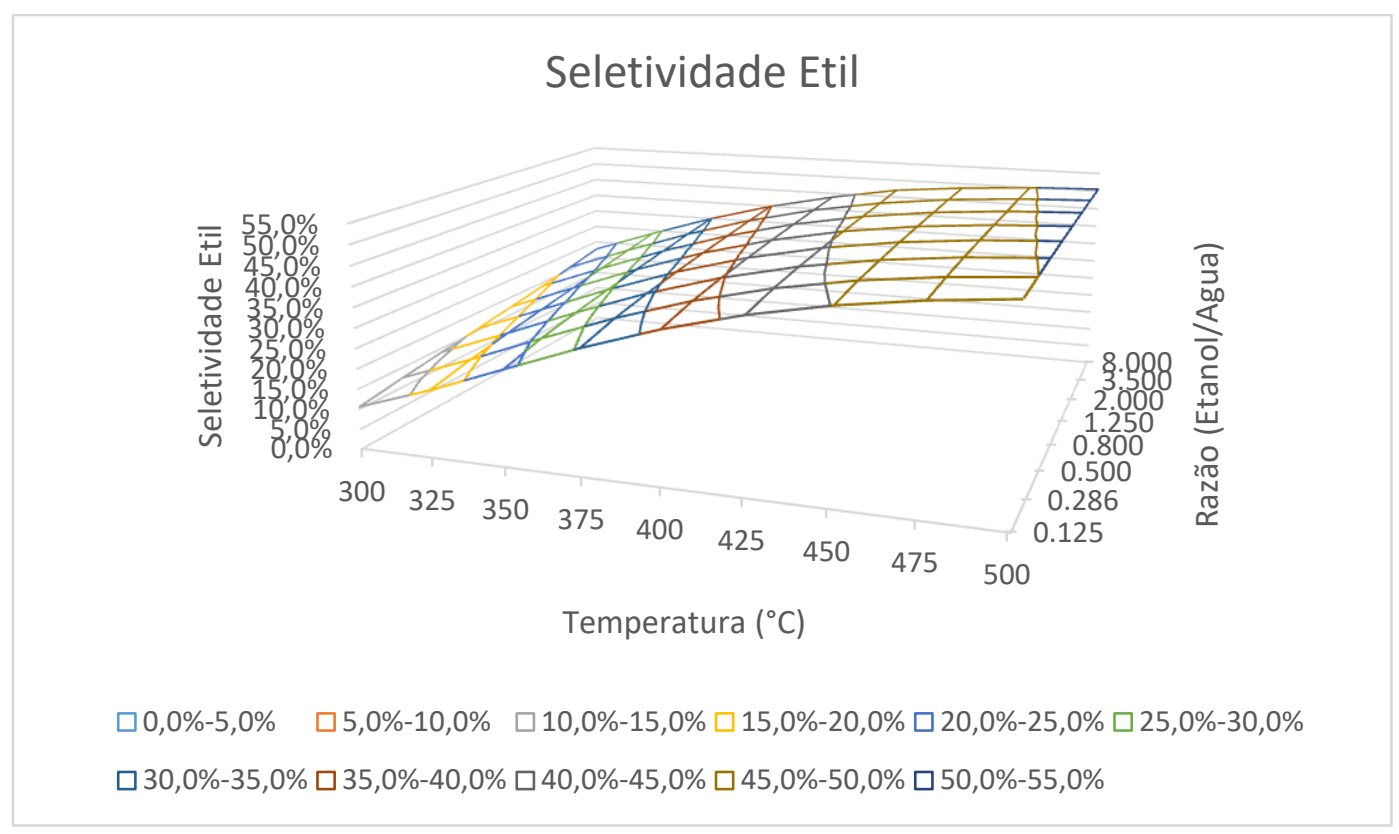

Figura 11 - Seletividade do etil.

No estudo realizado por Silva-Calpa (8) não é observada a formação do etil, que é um radical livre, o que se nota é a formação de eteno, que tem a composição química de $\mathrm{C}_{2} \mathrm{H}_{4}$, muito parecida com a do etil $\left(\mathrm{C}_{2} \mathrm{H}_{5}\right)$. Porém no equilíbrio metaestável calculado foi desconsiderada a formação do eteno por ela ser muito favorecida e impedir a formação da acetona, o que impossibilitaria a comparação com os dados experimentais. Isso sugere que com o uso dos catalisadores o etil que foi calculado deveria reagir e formar o eteno além de outras espécies que foi de fato observado nos experimentos de Silva-Calpa (8).

Outra espécie encontrada em quantidade relevante nos cálculos para certas temperaturas foi o 2-butino, sua seletividade se encontra na Tabela 10.

Tabela 10 - Seletividade do 2-butino

\begin{tabular}{r|rrrrrrrr}
\cline { 2 - 9 } & \multicolumn{7}{c}{ Seletividade 2-butino } \\
\cline { 2 - 9 } $\mathrm{T}\left({ }^{\circ} \mathrm{C}\right)$ & 0,125 & 0,286 & 0,500 & 0,800 & 1,25 & 2,00 & 3,50 & 8,00 \\
\hline 300 & $0,01 \%$ & $0,01 \%$ & $0,02 \%$ & $0,03 \%$ & $0,04 \%$ & $0,06 \%$ & $0,09 \%$ & $0,12 \%$ \\
325 & $0,03 \%$ & $0,05 \%$ & $0,07 \%$ & $0,10 \%$ & $0,13 \%$ & $0,18 \%$ & $0,24 \%$ & $0,32 \%$ \\
350 & $0,09 \%$ & $0,14 \%$ & $0,21 \%$ & $0,28 \%$ & $0,37 \%$ & $0,46 \%$ & $0,58 \%$ & $0,72 \%$ \\
375 & $0,24 \%$ & $0,38 \%$ & $0,53 \%$ & $0,68 \%$ & $0,85 \%$ & $1,03 \%$ & $1,24 \%$ & $1,47 \%$ \\
400 & $0,57 \%$ & $0,87 \%$ & $1,16 \%$ & $1,44 \%$ & $1,74 \%$ & $2,05 \%$ & $2,38 \%$ & $2,74 \%$ \\
425 & $1,18 \%$ & $1,75 \%$ & $2,24 \%$ & $2,72 \%$ & $3,19 \%$ & $3,67 \%$ & $4,13 \%$ & $4,65 \%$ \\
450 & $2,20 \%$ & $3,14 \%$ & $3,91 \%$ & $4,61 \%$ & $5,27 \%$ & $5,90 \%$ & $6,51 \%$ & $7,12 \%$ \\
475 & $3,72 \%$ & $5,10 \%$ & $6,17 \%$ & $7,09 \%$ & $7,91 \%$ & $8,67 \%$ & $9,37 \%$ & $10,0 \%$ \\
500 & $5,72 \%$ & $7,56 \%$ & $8,88 \%$ & $9,95 \%$ & $10,9 \%$ & $11,7 \%$ & $12,4 \%$ & $13,1 \%$
\end{tabular}


O 2-butino apenas é formado em quantidades relevantes em altas temperaturas e altas razões etanol/água. Como a seletividade da acetona não é tão influenciada pela razão etanol/água a altas temperaturas a formação de 2-butino pode ser evitada utilizando razões baixas. Isso pode ser feito para facilitar um processo de separação dos produtos finais.

Essa seletividade também pode ser vista no gráfico na Figura 12.

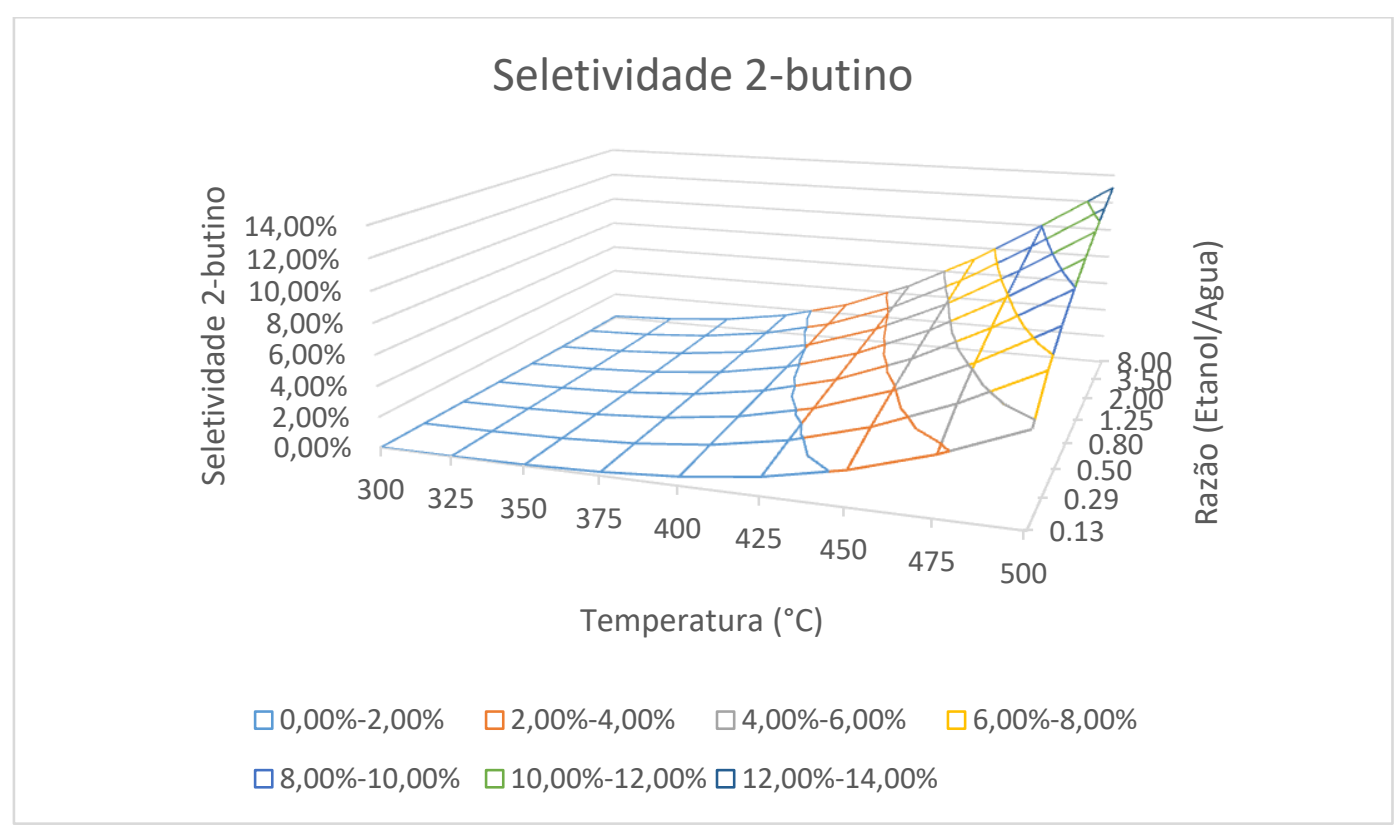

Figura 12 - Seletividade do 2-butino.

\subsection{5.}

\section{Atividade química do carbono}

Assim como na metanação, na produção da acetona também é interessante evitar a deposição de carbono sólido nos catalisadores, para ver se existe alguma condição em que o carbono não será formado foram feitos os cálculos da atividade química do carbono nos equilíbrios metaestáveis. Os resultados se encontram na Tabela 11. 
Tabela 11 - Atividade Química do Carbono

\begin{tabular}{r|rrrrrrrr}
\cline { 2 - 9 } & \multicolumn{7}{c}{ Atividade Quimica do Carbono } \\
\cline { 2 - 9 } $\mathrm{T}\left({ }^{\circ} \mathrm{C}\right)$ & 0,125 & 0,286 & 0,500 & 0,800 & 1,25 & 2,00 & 3,50 & 8,00 \\
\hline 300 & 0,98 & 1,20 & 1,40 & 1,62 & 1,86 & 2,14 & 2,46 & 2,84 \\
325 & 1,54 & 1,85 & 2,13 & 2,42 & 2,72 & 3,05 & 3,41 & 3,82 \\
350 & 2,30 & 2,73 & 3,09 & 3,45 & 3,81 & 4,19 & 4,60 & 5,03 \\
375 & 3,29 & 3,84 & 4,30 & 4,73 & 5,16 & 5,59 & 6,03 & 6,48 \\
400 & 4,52 & 5,22 & 5,77 & 6,27 & 6,75 & 7,22 & 7,68 & 8,15 \\
425 & 6,00 & 6,84 & 7,47 & 8,03 & 8,54 & 9,02 & 9,49 & 9,94 \\
450 & 7,70 & 8,65 & 9,33 & 9,90 & 10,4 & 10,9 & 11,3 & 11,7 \\
475 & 9,52 & 10,5 & 11,2 & 11,7 & 12,2 & 12,6 & 13,0 & 13,3 \\
500 & 11,3 & 12,3 & 12,9 & 13,4 & 13,7 & 14,0 & 14,3 & 14,5
\end{tabular}

Foi observado que em uma das condições o valor da atividade química do carbono é abaixo de 1 , isso ocorreu na razão de 0,125 e temperatura de $300^{\circ} \mathrm{C}$, mas como já foi observado antes, essa condição não é ideal para a formação da acetona.

Com isso pode se concluir que para todos os efeitos poderá ocorrer a formação do carbono sólido na forma de grafite nas condições de operação. Isso implica que a escolha dos catalisadores deverá priorizar sistemas menos suscetiveis a desativação e à formação de carbono sólido.

A atividade química do carbono também pode ser vista no gráfico na Figura 13.

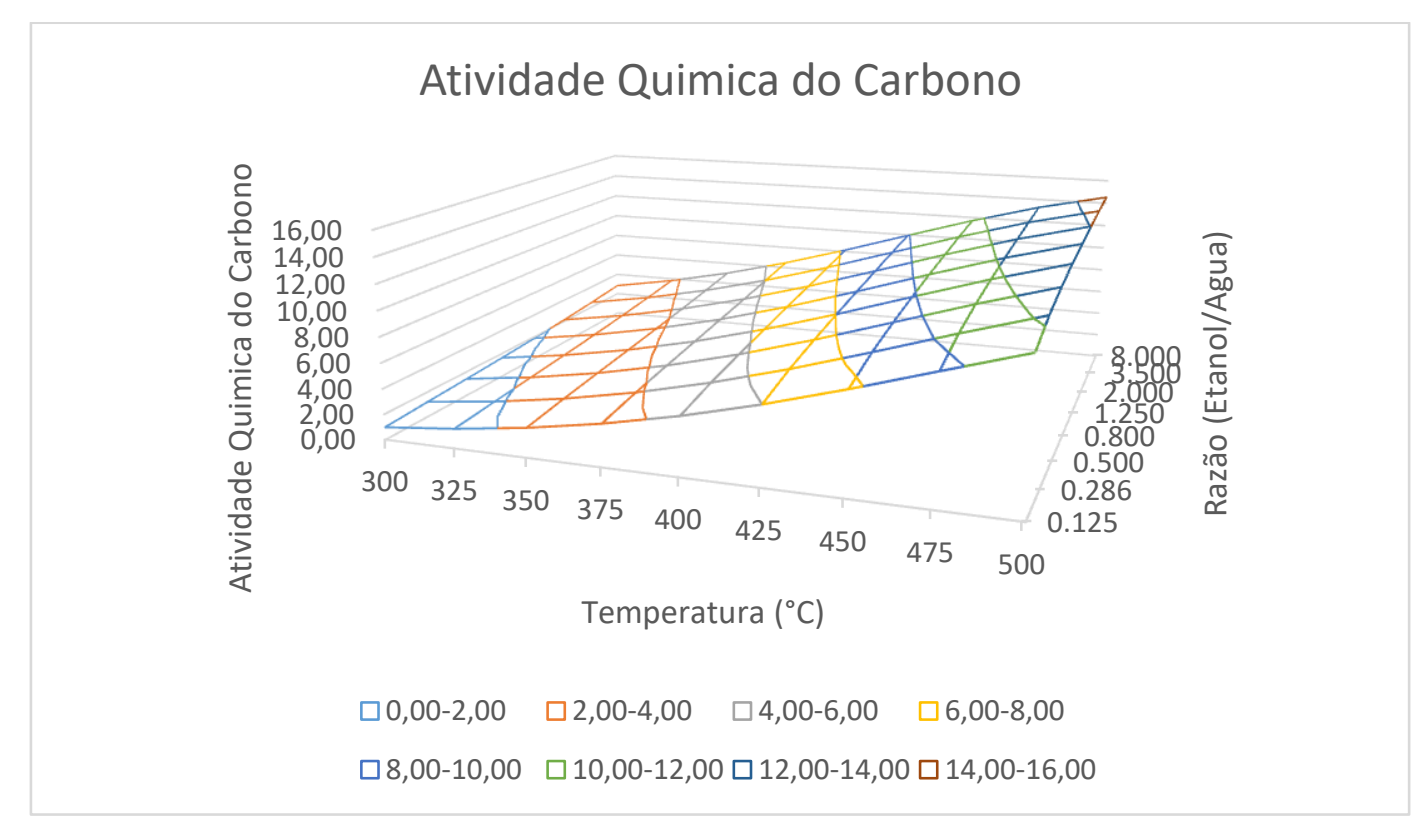

Figura 13 - Atividade Química do Carbono. 


\section{6 \\ Conclusão}

Os cálculos realizados de conversão de $\mathrm{CO}_{2}$ e formação de $\mathrm{CH}_{4}$ foram satisfatórios e condizentes com os valores encontrados em outros estudos.

A atividade química do carbono obtida nesses equilíbrios mostrou que em determinadas condições não ocorre a deposição de carbono sólido no equilíbrio da metanação, esse cálculo sugere a utilização da razão de $\mathrm{H}_{2} / \mathrm{CO}_{2}$ igual a 4, já que independentemente da temperatura, a atividade química é sempre menor que 1.

Esses resultados mostram que esse método de cálculo de equilíbrio utilizando o Thermo-Calc obtém valores semelhantes aos estudados em outros trabalhos e, portanto, valida em parte o banco de dados empregado. As condições ideais calculadas para a metanação foram de temperaturas de no máximo $300 \stackrel{\circ}{ } \mathrm{C}$ e a razão já citada.

$\mathrm{Na}$ segunda parte do trabalho foram calculados os equilíbrios metaestáveis para a formação de acetona a partir de etanol e água. Foram propostos equilíbrios metaestáveis para simular o efeito dos catalisadores, já que o equilíbrio termodinâmico mais estável não fornecia valores razoáveis para a seletividade da acetona

O equilíbrio metaestável encontrado como apropriado foi a temperatura $400{ }^{\circ} \mathrm{C}$, pressão de $101325 \mathrm{~Pa}$ para uma quantidade inicial de $91 \mathrm{~mol}$ de $\mathrm{N}_{2}$ como gás inerte de arraste, $8 \mathrm{~mol}$ de $\mathrm{H}_{2} \mathrm{O}$ e $1 \mathrm{~mol}$ de etanol e sugere que ao realizar os cálculos sejam desconsideradas as espécies: $\mathrm{CH}_{4}, \mathrm{H}_{3} \mathrm{~N}, \mathrm{H}_{2}, \mathrm{C}_{6} \mathrm{H}_{6}$, $\mathrm{C}_{2} \mathrm{H}_{6}, \mathrm{C}_{3} \mathrm{H}_{8}, \mathrm{C}_{2} \mathrm{H}_{4}, \mathrm{C}_{3} \mathrm{H}_{6} 2$ (propeno), $\mathrm{C}_{4} \mathrm{H}_{10}{ }_{1}$ (butano), $\mathrm{C}_{60}, \mathrm{C}_{4} \mathrm{H}_{8}{ }_{5}$ (2metilpropeno), $\mathrm{C}_{3} \mathrm{H}_{6}, \mathrm{C}_{4} \mathrm{H}_{8} 3$ (trans-2-buteno), $\mathrm{C}_{4} \mathrm{H}_{8} 2$ (cis-2-buteno), $\mathrm{C}_{4} \mathrm{H}_{8}{ }_{1} 1$ (1buteno), $\mathrm{CHN}-\mathrm{HCN}$ (cianeto de hidrogênio), $\mathrm{C}_{4} \mathrm{H}_{8}$ (ciclobutano), $\mathrm{C}_{4} \mathrm{H}_{6} 2$ (1,3butadieno) e $\mathrm{C}_{4} \mathrm{H}_{10 \_} 2$ (isobutano).

Nessas condições se obteve uma seletividade de $27 \%$ na formação da acetona. Após isso, foram variadas as condições iniciais do sistema e foi notado que a seletividade da acetona dependia da temperatura e da razão etanol/água. Foi visto que a temperaturas baixas o aumento da razão leva a um aumento da seletividade, mas isso diminui a temperaturas elevadas, o que mostra uma maior dependência da temperatura nessa reação. 
Foram calculadas as seletividades do etil e do 2-butino nesse equilíbrio, assim como a atividade química do carbono, todos esses cálculos indicam que as condições ideais para a formação da acetona seriam temperaturas elevadas $\left(425^{\circ} \mathrm{C}\right)$ e razões etanol/água baixas $(0,125)$.

Como conclusão final pode se considerar que o método de cálculo de equilíbrios utilizando o Thermo-Calc é um modelo válido para reproduzir os resultados de reações obtidos na prática, além de poder ser utilizado para simular os possíveis efeitos de catalisadores. 


\section{Sugestões de trabalhos futuros}

Seria interessante a utilização do método visto no presente trabalho junto com experiências práticas das reações para uma melhor verificação dos cálculos realizados.

Também seria interessante a utilização desse método para os cálculos de outras reações conhecidas, não apenas da metanação, para validar ainda mais o método utilizado.

Estudar reações que tenham uma maior influência da pressão nos resultados, já que neste trabalho todos os cálculos foram realizados a uma mesma pressão, isso seria interessante para ver se o método continua sendo consistente

com

essas

diferenças. 


\section{8}

\section{Referências bibliográficas}

1. REISMAN, D. J., International programme on chemical safety. Enviromental health criteria 207. Acetone. Environmental Protection agency, Cincinnati, USA, 1998.

2. RODRIGUES, C. P., ZONETTI, P. DA C., APPEL, L. G., Chemicals from ethanol: the acetone synthesis from ethanol employing Ce0.75Zr0.25O2, ZrO2 and $\mathrm{Cu} / \mathrm{ZnO} / \mathrm{Al2O}$. Chemistry Central Journal, 11, 30., 2017; http://doi.org/10.1186/s13065-017$\underline{0249-5}$.

3. TYMAN, J. H. P., Synthetic and natural phenols, Elsevier Science, 1996.

4. KIRK-OTHMER, Encyclopedia of Chemical Technology, A to Alkaloids, Fourth Edition, Wiley, 1991.

5. SIFNIADES, S., Ullmann's encyclopedia of industrial chemistry Acetone, Wiley, 2010.

6. U.S DEPARTMENT OF HEALTH AND HUMAN SERVICES, Toxicological profile for phenol, 2008.

7. CONAB, C., Acompanhamento da safra brasileira Cana-deaçúcar, 2017.

8. CALPA, L. D. R. S., Promoção das propriedades óxido redutoras da zircônia monoclínica dopada com zinco na síntese de acetona a partir do etanol. Tese de doutorado. Pontifícia Universidade Católica do Rio de Janeiro, 2015.

9. GAO, J., WANG, Y., PING, Y., HU, D., XU, G., GU, F., SU, F., A thermodynamic analysis of methanation reactions of carbon oxides for the production of synthetic natural gas, RSC Advances, 2012, 2, 2358-2368.

10. SU, X., XU, J., LIANG, B., DUAN, H., HOU, B., HUANG, Y., Catalytic carbon dioxide hydrogenation to methane: A review 
of recent studies. Journal of Energy Chemistry 2016; 25(4): 553565.

11. GOODMAN, D., Methanation of Carbon Dioxide. University of California; 2013.

12. RÖNSCH, S., SCHNEIDER, J., MATTHISCHKE, S., SCHLÜTER, M., GÖTZ, M., LEFEBVRE, J., PRABHAKARAN, P., BAJOHR, S., Review on methanation - From fundamentals to current projects. Fuel 2016; 166: 276-296; https://doi.org/10.1016/j.fuel.2015.10.111.

13. SUTTON, D., KELLEHER, B., ROSS, J. R. H., Review of literature on catalysts for biomass gasification, Fuel Processing Technology 73 (2001) 155-173.

14. LEFFLER, J. E., GRUNWALD, E., Rates and equilibria of organic reactions: As treated by statistical, thermodynamic, and extrathermodynamic methods, Dover Publications, Inc. 1989.

15. WINTERBONE, D., TURAN, A., Advanced Thermodynamics for engineers, Second Edition, Elsevier Science, 1997.

16. KUMAR, B., KUMAR, S., KUMAR, S., Methane production by butanol decomposition: thermodynamic analysis. Chemical and Bioprocess Engineering Trends and Developments p. 101-108. 2015.

17. AVILLEZ, R., R. DE, Termodinâmica dos Materiais e processos, PUC-RIO, Rio de Janeiro, 2016.

18. PORTER, D. A., EASTERLING, K. E., SHERIF, M. Y., Phase Transformations in Metals and Alloys, Third Edition, CRC Press, 2009.

19. BOUDART, M., In Perspectives in Catalysis, J. M. Thomas, K. I. Zamaraev (Eds.), Blackwell, Oxford, 1992, p.183.

20. DUMESIC, J. A., HUBER, G. W., BOUDART, M., Principles of Heterogenous Catalysis. In Handbook of Heterogeneous Catalysis (eds G. Ertl, H. Knözinger, F. Schüth and J. Weitkamp), 2008. Doi:10.1002/9783527610044. hetcat0001. 
21. COMSOL MULTIPHYSICS, Carbon Deposition in Heterogeneous Catalysis SOLVED WITH COMSOL REACTION ENGINEERING LAB 3.5;

22. BIAN, Z., MENG, X., TAO, M., LV, Y., XIN, Z., Uniform Ni particles on amino-functionalized SBA-16 with excellent activity and stability for syngas methanation. Journal of Molecular Catalysis A: Chemical, v.417, p. 184-191, 2016

23. COMITTEE ON AMERICA'S ENERGY FUTURE, NATIONAL ACADEMY OF SCIENCES, NATIONAL ACADEMY OF ENINEERING AND NATIONAL RESEARCH COUNCIL OF THE NATIONAL ACADEMIES, America's Energy Future: Technology and Transformation, 2009, Summary ed., 11, 16, 102.

24. DUYAR, M. S., tReVIÑO, M. A. A., FARRAUto, R. J., Dual function materials for $\mathrm{CO} 2$ capture and conversion using renewable H2, Applied catalysis B: Environmental 168-169 (2015) 370-376

25. FECHETE, I. Paul Sabatier The father of the chemical theory of catalysis, Comptes RendusChimie, 2016, http://dx.doi.org/10.1016/j.crci.2016.08.006

26. MILLS, G. A., STEFFGEN, F. W., Catalytic Methanation, Catalysis Reviews, $\quad 1974, \quad 8: 1, \quad$ 159-201, DOI:10.1080/01614947408071860.

27. NAHAR, G. A., MADHANI, S. S., Thermodynamics of hydrogen production by the steam reforming of butanol: Analysis of inorganic gases and light hydrocarbons. International Journal of Hydrogen Energy, 2010, v. 35 p. 98-109.

28. SEHESTED, J., DAHL, S. JACOBSEN, J., ROSTRUP-NIELSEN, J. R., Methanation of $\mathrm{CO}$ over Nickel: Mechanism and Kinetics at High H2/CO Ratios, The Journal of Physical Chemistry B, 2005, 109 (6) p.2432-2438

29. GIERLICH, H. H., FREMERY, M., SKOV, A., ROSTRUP-NIELSEN, J. R., Deactivation Phenomena of a Ni-based Catalyst for High Temperature Methanation, Studies in Surface Science and Catalysis, v. 6, 1980, p. 459-469. 
30. MCCARTY, J. G., WISE, H., Hydrogenation of surface carbono on alumina-supported nickel, Journal of Catalysis, v57, Issue 3 , 1979, p.406-416.

31. XU, J., FROMENT, G. F., Methane Steam Reforming, Methanation and Water-Gas shift: 1. Intrinsic Kinetics. AIChe Journal, v.35, No1, p 88-96, January 1989

32. WANG, W., GONG, J., Methanation of carbono dioxide: na overview, Frontiers of Chemical Science and Engineering, 5(1); 210,2011

33. AGNELLI, M., KOLB, M., MIRODATOS, C., CO hydrogenation on a nickel catalyst: 1. Kinetics and modeling of a lowtemperature sintering process, Journal of Catalysis, 1994, 148(1): 9-21

34. SRI CONSULTING, Acetone, Chemical Economics Handbook, November, 2016

35. ICIS, Acetone Prices, Market and Analysis. 2018. Disponível em http://www.icis.com/chemicals/acetone/. Acesso em 1 Agosto 2018.

36. MURTHY, R. S., PATNAIK, P., SIDHESWARAN, P., JAYAMANI, M., Conversion of Ethanol to Acetone over Promoted Iron Oxide Catalysis. Journal of Catalysis, v.109, p.298-302, 1988.

37. NAKAJIMA, T., NAMETA, H., MISHIMA, S., TANABEB,K., A Higly Active and Higly Selective Oxide Catalyst for the Conversion of Ethanol to Acetone in the Presence of Water Vapour. Journal of material chemistry. v.4, n.6 p.-853-858, 1994.

38. YEE, A., MORRISON, S. J., IDRISS, H. A study of the Reactions of Ethanol on $\mathrm{CeO} 2$ and $\mathrm{Pd} / \mathrm{CeO} 2$ by Steady State Reactions, Temperature Programmed Desorption, and In Situ FT-IR. Journal of Catalysis, v. 186, p.279-295, 1999.

39. IDRISS, H., SEEBAUER, E. G. Reactions of etanol over metal oxides. Journal of Molecular Catalysis A: Chemical, v. 152, n.1-2, p.201-212, 2000.

40. NISHIGUCHI, T., MATSUMOTO, T., KANAI, H., UTANI, K., MATSUMURA, Y., SHEN, W., IMAMURA, S., Catalytic steam 
reforming of etanol to produce hydrogen and acetone. Applied Catalyst A: General, v.279, Issues 1-2, p.273-277, 2005.

41. RODRIGUES, C. P., ZONETTI, P. C., SILVA, C. G, GASPAR, A.B., APPEL, L. G., Chemicals from Ethanol - The acetone one-pot synthesis. Applied Catalysis A: General, v. 458, p. 111-118, 2013.

42. ANDERSSON, J. O., HELANDER, T., HÖGLUND, L., SHI, P. F., SUNDMAN, B., (2002). Thermo-Calc and DICTRA, Computational tools for materials science. Calphad, 26, 273-312.

43. THERMO-CALC CONSOLE MODE USER GUIDE, VERSION $2015^{\mathrm{a}}$

44. Thermo-Calc Software SSUB3 database.

45. QtiPlot, https://www.qtiplot.com/download.html.

46. COX, J. D., WAGMAN, D. D., MEDVEDEV, V. A., CodATA Key Values for Thermodynamics, Hemisphere Publishing Corp., New York, 1984.

47. CHASE, M. W., JR., NIST-JANAF Thermochemical Tables, Fourth Edition, Journal of Physical and Chemical Reference Data, Monograph 9, 1998

48. SMIRNIOTIS, P., GUNUGUNURI, K., Water Gas Shift Reaction: Research Developments and Applications, Elsevier Science, 2015 